\title{
Explaining Output Volatility: The Case of Taxation
}

\author{
Olaf POSCH
}

CESIFO WORKING PAPER NO. 2751

CAtegory 6: Fiscal Policy, Macroeconomics AND Growth

August 2009

An electronic version of the paper may be downloaded
- from the SSRN website: $\quad$ www.SSRN.com
- from the RePEc website:
- from the CESifo website: 


\title{
Explaining Output Volatility: The Case of Taxation
}

\begin{abstract}
This paper presents empirical evidence against the popular perception that macro volatility is exogenous. We obtain tax effects on macro aggregates in the stochastic neoclassical model. Taxes are shown to affect the second moment of output growth rates without affecting the first moment. Exploiting heterogeneity patterns in a panel of OECD countries, we estimate tax effects on macro volatility, explicitly modeling the unobserved variance process. We find a strong empirical link between taxes and output volatility. Accounting for non-stationarity of taxes and output volatility, we find empirical evidence of a cointegrating relationship.
\end{abstract}

JEL Code: E32, E62.

Keywords: macroeconomic volatility, tax effects, continuous-time DSGE models.

\author{
Olaf Posch \\ Aarhus University \\ School of Economics and Management \\ Building 1322 \\ Bartholins Allé 10 \\ DK - 8000 Århus C \\ Denmark \\ oposch@econ.au.dk
}

July 2009

Parts of this paper were written at the University of Hamburg. The author appreciates financial support from the Center for Research in Econometric Analysis of Time Series funded by The Danish National Research Foundation. I thank Bernd Lucke, Roberto Perotti, Valerie Ramey, and Michael Sørensen for comments and an anonymous referee for numerous suggestions. I am indebted to Klaus Wälde for extensive discussions on the tax-volatility link. I am grateful to the Verein für Socialpolitik for having awarded the paper with the Reinhard Selten Best Paper prize at the annual meeting in Graz 2008. 


\section{Introduction}

This paper presents empirical evidence against the popular perception that macro volatility is exogenous. Intuitively, the variance of output growth depends on the variance of the shocks to productivity, the variance of factor input dynamics, such as hours worked or capital, and their covariances. In dynamic stochastic general equilibrium (DSGE) models (in the tradition of Kydland and Prescott 1982, Long and Plosser 1983), the variance of the innovations to technology is considered to be exogenous. ${ }^{1}$ This paper shows that the variance of factor dynamics is not exogenous, but explained by taxes.

Our empirical motivation stems from the fact that major US tax reforms took place around the point in time where the break in output volatility is usually identified. ${ }^{2}$ In this period, the focus of US policy debates was on the Economic Recovery Tax Act (ERTA), the first of the Reagan tax cuts (also known as Kemp-Roth Tax Cut) with large economic effects (Auerbach and Slemrod 1997). Similarly, the moderation of output volatility in the UK was accompanied by massive tax cuts (Giles and Johnson 1995). ${ }^{3}$ Effective tax rates indeed show abrupt changes during the volatility slowdown for both the US and the UK, and differ substantially across countries (Mendoza et al. 1994). Our objective is to investigate whether there is a general link between taxes and output volatility.

Our work builds on Posch and Wälde (2006), who obtain closed-form measures in a model where macro volatility is fully endogenous and identify three channels through which taxes can have effects on output volatility. This paper now thoroughly studies the component which is present in any non-linear DSGE model and estimates the effects empirically. For this objective we use a continuous-time formulation, which allows us to derive tax effects on output growth volatility under Normal uncertainty. ${ }^{4}$ It turns out that second-order approximation schemes are necessary in order to uncover tax effects on output volatility in the discrete-time version (Schmitt-Grohé and Uribe 2004), which makes any analytical attempt difficult.

The contribution of this paper is primarily empirical. One of its most surprising findings is the strong empirical link between tax rates and output volatility. Using a panel of OECD countries from 1970 to 2004, our results demonstrate that the effects of taxes are robust and of economic relevance. Together with other controls, effective tax rates account for up to two thirds of the variation in output volatility. Conforming with theoretical results, taxes on labor income and corporate income are statistically

\footnotetext{
${ }^{1}$ The stochastic shocks can be endogenous as in the growing through cycles literature (Bental and Peled 1996, Matsuyama 1999, Francois and Lloyd-Ellis 2003, 2008, Wälde 2005).

${ }^{2}$ The break for the US is often dated in 1984Q1 or 1984Q2 (Kim and Nelson 1999, McConnel and Perez-Quiros 2000) while other estimates range from 1982Q4 to 1985Q3 (Stock and Watson 2002).

${ }^{3}$ Cecchetti et al. (2006) identify two breaks in 1981Q2 and 1991Q4 for the UK.

${ }^{4}$ An introduction to continuous-time DSGE models can be found in Turnovsky (2000).
} 
significant and negatively correlated to output volatility, while the capital tax has the opposite effect. For the consumption tax we do not find statistically significant effects. These results are found to be robust to the employed estimation method and potential non-normality of the residuals, i.e., using bootstrapped errors.

From a theoretical perspective, we show that in the stochastic neoclassical model taxes affect the second moment rather than the first moment of output growth rates. In particular, we show that tax effects are not unidirectional specifying numerical results of Greenwood and Huffman (1991). Using closed-form measures, we find negative effects from the income tax and the investment tax, whereas the tax on wealth amplifies macro volatility measured by the standard deviation of output growth rates. The consumption tax has no effect. Output volatility can be decomposed into the variance of the exogenous impulses and a component that is governed by fundamentals which reflects the variance factor input dynamics. Taxes affect the latter by distorting the consumption-savings decision, which affects the variability of the capital rewards and finally translates into a change in macro volatility.

We are aware of only one other paper that emphasizes changes in factor dynamics and output volatility: the contribution of Stiroh (2009). ${ }^{5}$ His innovative paper takes a production perspective and develops a "volatility accounting" methodology to quantify the sources of volatility. One difference between our papers is that our empirical approach allows us to trace back changes in output volatility to changes in structural parameters that an accounting framework cannot handle. Further, our theoretical model illustrates the effects of taxes on factor dynamics, i.e., capital dynamics.

There is now a large literature on macro volatility. Much of it focuses on less developed countries and financial development (Denizer et al. 2002, Lensink and Scholtens 2004) or institutions (Acemoglu et al. 2003). Our estimates confirm a robust link between output volatility and variables including the mean output growth, the variability of real effective exchange rates, measures of monetary policy and openness. Other controls are either not found to be statistically significant among OECD countries, such as variables based on government expenditures, or not robust, such as financial development.

This paper is closely related to studies investigating why output growth has become less volatile in the US and in many other OECD countries (among others McConnel and Perez-Quiros 2000, Stock and Watson 2002, 2005). ${ }^{6}$ From a demand perspective, the literature emphasizes technological factors (e.g. inventory management) and improved central bank policy (e.g. credible monetary policy, inflation targeting). From a produc-

\footnotetext{
${ }^{5}$ Jaimovich and Siu (2009) establish the link between demographics and macro volatility.

${ }^{6}$ The paper of Stock and Watson (2002) surveys a substantial literature on the big moderation. Recent work includes Cecchetti et al. (2006), Justiniano and Primiceri (2008), Canova (2009) and Stiroh (2009).
} 
tion perspective, however, changes in labor market dynamics are identified as potential explanations (Stiroh 2009). We are unaware of any empirical studies linking output volatility, or volatility of factor dynamics, to tax rates. Our finding that taxes should be added to the potential explanations is new and complementary to the previous work.

In the paper we proceed as follows. Section 2 studies tax effects on output volatility in a neoclassical model. Section 3 briefly describes the estimation strategy and the underlying measures. Section 4 presents the empirical results using various specifications. Section 5 provides a summary and concluding remarks.

\section{Taxes and output volatility}

This section provides a theoretical model for tax effects on output volatility. It focuses on the propagation mechanism identified in Posch and Wälde (2006). In its structure, it describes a continuous-time real business cycle model with a government sector. For this economy, we obtain a closed-form measure of output volatility based on growth rates.

\subsection{The model}

As the technological setup of the economy is standard, we keep the outline of the model brief. The introduction of government activities and the implications for household behavior will be presented in more detail. Most of the derivations are in the appendix.

Production possibilities. The single good is produced according to a Cobb-Douglas function,

$$
Y_{t}=A_{t} K_{t}^{\alpha} L^{1-\alpha}
$$

where $L$ is total constant labor supply, $K_{t}$ is the aggregate capital stock. Uncertainty enters through an geometric process for total factor productivity, $A_{t}$, driven by a standard Brownian motion $B_{t}$,

$$
d A_{t}=\mu A_{t} d t+\eta A_{t} d B_{t}
$$

Output $Y_{t}$ is used for producing consumption goods $C_{t}$ and investment goods $I_{t}$. The aggregate capital stock increases if gross investment $I_{t}$ exceeds depreciation $\delta K_{t}$,

$$
d K_{t}=\left(I_{t}-\delta K_{t}\right) d t
$$

Government. The government levies taxes on income, $\tau_{i}$, on wealth, $\tau_{a}$, on consumption expenditures, $\tau_{c}$, and on investment expenditures, $\tau_{k}$. It cannot save or run debt and uses all revenues to provide basic government services $G$,

$$
G_{t}=\tau_{i}\left(Y_{t}-\delta K_{t}\right)+\tau_{k}\left(I_{t}-\delta K_{t}\right)+\tau_{c} C_{t}+\tau_{a}\left(1+\tau_{k}\right) K_{t} \geq 0
$$


We assume a myopic government simply providing basic government services without interest in neither stabilization policy nor optimal taxation. The tax structure thus is exogenously given to the model. Similarly, the absence of debt therefore is not relevant because we want to illustrate the incentive effects of distortionary taxation on output growth volatility of an elsewise frictionless economy. One could interpret the taxes as wedges between competitive prices and observed prices (Chari et al. 2007). Additional effects through the channel of fiscal debt are beyond the scope of this paper.

Preferences. The economy has a large number of representative households, who maximize expected utility, given by the integral over utility, $u=u\left(c_{t}\right)$, resulting from consumption flows, $c_{t}$, discounted at the subjective rate of time preference, $\rho$,

$$
U_{0}=E_{0} \int_{0}^{\infty} e^{-\rho t} u\left(c_{t}\right) d t, \quad u\left(c_{t}\right)=\frac{c_{t}^{1-\sigma}}{1-\sigma}, \quad \sigma>0
$$

where instantaneous utility is characterized by constant relative risk aversion.

The budget constraint of the representative household reads

$$
d a_{t}=\left(\left(\frac{1-\tau_{i}}{1+\tau_{k}}\left(r_{t}-\delta\right)-\tau_{a}\right) a_{t}+\frac{1-\tau_{i}}{1+\tau_{c}} w_{t}-c_{t}\right) d t
$$

where $w_{t}$ denotes the real wage rate, and $r_{t}$ the rental rate of capital, both before tax.

Equilibrium properties. In equilibrium, factors are rewarded by $w_{t}=Y_{L}$, and $r_{t}=Y_{K}$ (value marginal product), respectively. Market clearing demands $Y_{t}=C_{t}+I_{t}+G_{t}$, or

$$
\left(1-\tau_{i}\right) Y_{t}=\left(1+\tau_{c}\right) C_{t}+\left(1+\tau_{k}\right) I_{t}+\left(1+\tau_{k}\right)\left(\tau_{a}-\frac{\tau_{i}+\tau_{k}}{1+\tau_{k}} \delta\right) K_{t}
$$

where we inserted the government budget constraint (4). Note that the quantities $C_{t}$ and $I_{t}$ are after taxation. Since markets are perfectly competitive, the producer price of the production, consumption, and investment good will be identical,

$$
p_{t}^{Y}=p_{t}^{C}=p_{t}^{K}
$$

When consumption and investment goods are sold, they are taxed differently such that consumer prices are $\left(1+\tau_{c}\right) p_{t}^{C}$ and $\left(1+\tau_{k}\right) p_{t}^{K}$, respectively. In order to rule out arbitrage between different types of goods, we assume that a unit of production is useless for other purposes once it is assigned for a specific purpose.

Solving the model requires the first-order condition for consumption, the aggregate capital accumulation constraint (3), the goods market equilibrium (7), and optimality conditions of perfectly competitive firms. Thus we obtain a system of equations determining, given boundary conditions, the time paths of $C_{t}, K_{t}, Y_{t}, G_{t}$, and $w_{t}$ and $r_{t}$.

The traditional approach considers a stationary system and employs approximation techniques to study the transitional dynamics. Recent research emphasizes higher-order 
approximation schemes (Schmitt-Grohé and Uribe 2004). In order to illustrate tax effects on macro volatility, we use parametric restrictions under which the model has explicit solutions. The main advantage is the availability of closed-form expressions for the densities of macro aggregates and measures of output volatility.

\section{$2.2 \quad$ Explicit solutions}

Though our economy is set up in continuous time, we easily obtain discrete-time observed output growth rates by integrating the stochastic differential of log output using (1),

$$
\begin{aligned}
d Y_{t} & =\left(\mu+\alpha\left(I_{t} / K-\delta\right)\right) Y_{t} d t+\eta Y_{t} d B_{t} \\
\Leftrightarrow d \ln Y_{t} & =\left(\mu-\frac{1}{2} \eta^{2}+\frac{1-\tau_{i}}{1+\tau_{k}} r_{t}-\alpha \frac{1+\tau_{c}}{1+\tau_{k}} C_{t} / K_{t}-\alpha\left(\tau_{a}-\frac{1-\tau_{i}}{1+\tau_{k}} \delta\right)\right) d t+\eta d B_{t}
\end{aligned}
$$

where we used

$$
I_{t}=\frac{1-\tau_{i}}{1+\tau_{k}} Y_{t}-\frac{1+\tau_{c}}{1+\tau_{k}} C_{t}-\left(\tau_{a}-\frac{\tau_{i}+\tau_{k}}{1+\tau_{k}} \delta\right) K_{t}
$$

It describes a controlled stochastic differential equation (SDE) which, for solving, demands more information about the behavior of households. In general equilibrium, their decisions in turn determine the process for the capital stock and thus capital rewards. Hence, the exogenous shocks enter output growth rates both contemporaneously and inter-temporally because they are propagated through capital accumulation.

Theorem 2.1 If the output elasticity of capital equals the parameter of the utility function, $\alpha=\sigma$, consumption is a linear function of the capital stock, $C_{t}=\frac{1+\tau_{k}}{1+\tau_{c}} \phi K_{t}{ }^{7}$

$$
\phi=\frac{\rho}{\sigma}+\frac{1-\sigma}{\sigma}\left(\frac{1-\tau_{i}}{1+\tau_{k}} \delta+\tau_{a}\right)
$$

Proof. Appendix A.2.1.

Corollary 2.2 The rental rate of capital follows

$$
d r_{t}=c_{1} r_{t}\left(c_{2}-r_{t}\right) d t+\eta r_{t} d B_{t}
$$

where $c_{1} \equiv \frac{1-\alpha}{\alpha} \frac{1-\tau_{i}}{1+\tau_{k}}$, and $c_{2} \equiv \frac{1+\tau_{k}}{1-\tau_{i}}\left(\frac{\alpha}{1-\alpha} \mu+\rho+\frac{1-\tau_{i}}{1+\tau_{k}} \delta+\tau_{a}\right)$.

The SDE in (11) is a geometric reverting diffusion process, also known as the stochastic Verhulst equation (Sørensen 1991). Accordingly, $c_{2}$ defines the non-stochastic steady state to which $r_{t}$ tends, and $c_{1}$ is the speed of reversion. It can be shown that $r_{t}$ has a limiting Gamma distribution where all moments are available in closed form (Merton 1975).

\footnotetext{
${ }^{7}$ This parametric restriction is fairly well established in macroeconomics (Chang 1988, Xie 1991, 1994, Boucekkine and Tamarit 2004, Wälde 2005, Smith 2007).
} 
Corollary 2.3 The growth rate of output per unit of time, $\Delta y_{t} \equiv \ln Y_{t}-\ln Y_{t-\Delta}$, reads

$$
\Delta y_{t}=\left(\mu-\frac{1}{2} \eta^{2}\right) \Delta+\sigma\left(\ln C_{t}-\ln C_{t-\Delta}\right)+\eta\left(B_{t}-B_{t-\Delta}\right)
$$

The result in (12) is remarkable as it implies a simple linear relation between output and consumption growth rates, which clearly depends on the restriction $\alpha=\sigma{ }^{8}$ This solution, however, neatly illustrates the propagation mechanism. As the bottom line, households in general equilibrium affect the short-run dynamics of the output growth rate by their consumption-saving decision. In what follows we show that (long-run) tax effects on the volatility of growth rates operate exactly through this channel.

Intuitively, as from the standard Euler equation, the growth rate of consumption refers to the capital rewards in (11). Indeed, in the proof to Corollary 2.3, we show that

$$
\sigma\left(\ln C_{t}-\ln C_{t-\Delta}\right)=\frac{1-\tau_{i}}{1+\tau_{k}} \int_{t-\Delta}^{t} r_{s} d s-\left(\rho+\tau_{a}+\frac{1-\tau_{i}}{1+\tau_{k}} \delta\right) \Delta .
$$

It can be interpreted as the 'discrete-time' version of the Euler equation for $\alpha=\sigma$.

\subsection{Tax effects in the stochastic neoclassical model}

We are now interested in the tax effects on the output growth rate per unit of time. Clearly as a standard result, taxation affects growth rates in the short run directly as well as indirectly via capital accumulation, which has already been widely discussed in the growth literature. In order to derive effects of taxation on other moments of the distribution of growth rates, we study the long-run effects or the unconditional moments.

Using output growth rates in (12), it can easily be shown that (cf. Appendix A.3)

$$
\begin{aligned}
E\left(\Delta y_{t}\right) & =\frac{1}{1-\alpha}\left(\mu-\frac{1}{2} \eta^{2}\right) \Delta, \\
\operatorname{Var}\left(\Delta y_{t}\right) & =\sigma^{2} \operatorname{Var}\left(\ln C_{t}-\ln C_{t-\Delta}\right)+\eta^{2} \Delta .
\end{aligned}
$$

Intuitively, we obtain these results for the following reasons. First, the mean does not depend on taxes because it is only driven by the exogenous process in factor productivity. Thus consumption and output must grow asymptotically at the same rate. Second, since optimal consumption is a linear function of the capital stock, which is a deterministic process, consumption growth rates and the Brownian motion increments are uncorrelated.

Unfortunately, the variance of consumption growth rate is complicated because it refers to the variance of the integrated process of capital rewards in (13). Because of the

\footnotetext{
${ }^{8}$ The key mechanism is that consumption becomes linear in the capital stock, which determines capital rewards in (11). Another solution with similar dynamics for capital rewards is provided in the appendix.
} 
Table 1: Tax effects in the stochstic neoclassical model

\begin{tabular}{lcccc}
\hline \hline & \multicolumn{4}{c}{ Marginal tax effects } \\
& $($ income $)$ & $\begin{array}{c}\tau_{c} \\
\text { (cons.) }\end{array}$ & (investment) & $\tau_{k}$ \\
\hline$E\left(\Delta y_{t}\right)$ & 0 & 0 & 0 & (wealth) \\
\hline $\operatorname{Var}\left(\Delta y_{t}\right)$ & $-\frac{\alpha}{1-\alpha} \frac{1}{1+\tau_{k}} \delta \frac{1}{2} \eta^{2} \Delta^{2}$ & 0 & $-\frac{\alpha}{1-\alpha} \frac{1-\tau_{i}}{\left(1+\tau_{k}\right)^{2}} \delta \frac{1}{2} \eta^{2} \Delta^{2}$ & $\frac{\alpha}{1-\alpha} \frac{1}{2} \eta^{2} \Delta^{2}$
\end{tabular}

Notes: This table reports the marginal tax effects of time-invariant tax rates on volatility and growth in the neoclassical model. The measures include the mean and variance of output growth per unit of time $\Delta$, neglecting third-order terms.

Table 2: Calibrated tax semi-elasticities and a plausible tax scenario for the UK

\begin{tabular}{lcccccrr}
\hline \hline & $\begin{array}{l}\text { (a) Calibration } \\
\end{array}$ & \multicolumn{3}{c}{$(b)$ Tax semi-elasticities } & \multicolumn{2}{c}{$(c)$ Tax reform } \\
& no taxes & $\begin{array}{c}\tau_{i} \\
\text { (income) }\end{array}$ & $\begin{array}{c}\tau_{c} \\
(\text { cons.) }\end{array}$ & $\begin{array}{c}\tau_{k} \\
\text { (investment) }\end{array}$ & $\begin{array}{c}\tau_{a} \\
\text { (wealth) }\end{array}$ & baseline & effect \\
\hline$E\left(\Delta y_{t}\right)$ & 0.0188 & 0 & 0 & 0 & 0 & 0.0188 & 0 \\
$\operatorname{Var}\left(\Delta y_{t}\right)$ & 0.0007 & $-0.10 \%$ & 0 & $-0.10 \%$ & $+1.29 \%$ & 0.0008 & $-7.04 \%$ \\
$\operatorname{E}\left(r_{t}\right)$ & 0.1091 & $+0.32 \%$ & 0 & $+0.31 \%$ & $+9.17 \%$ & 0.2043 & $-25.06 \%$ \\
$\operatorname{Var}\left(r_{t}\right)$ & 0.0001 & $+1.33 \%$ & 0 & $+1.32 \%$ & $+9.17 \%$ & 0.0003 & $-2.58 \%$
\end{tabular}

Notes: This table illustrates tax effects on macro variables for technology parameters $(\rho, \alpha, \sigma, \delta)=(.02, .75, .75, .075)$, other parameters $(\mu, \eta)=(.001, .025)$, and taxes $\left(\tau_{i}, \tau_{c}, \tau_{k}, \tau_{a}\right)=(0,0,0,0)$. It shows $(a)$ the implied mean and variance of annual output growth rates, and the mean and variance of before-tax capital rewards, $(b)$ percentage changes due to a one percentage point increase in the tax rate, and $(c)$ a tax scenario for the UK from the 1980s to the 1990s (cf. Figure 2). The baseline calibration is $\left(\tau_{i}, \tau_{c}, \tau_{k}, \tau_{a}\right)=(0.35,0.1,0,0.05)$ while the post-reform values are $\left(\tau_{i}, \tau_{c}, \tau_{k}, \tau_{a}\right)=(0.5,0.1,0,0.005)$, which encompasses a cut in the tax on wealth, $\tau_{a}$, and an increase in the income tax, $\tau_{i}$.

non-linear dynamics in (11), this variance is not explicitly available. ${ }^{9}$ Using closed-form expansions, the variance of consumption growth is (see Appendix A.3)

$$
\operatorname{Var}\left(\ln C_{t}-\ln C_{t-\Delta}\right)=\left(c_{1} c_{2}-\frac{1}{2} \eta^{2}\right)\left(\frac{1}{1-\alpha}\right)^{2} \frac{1}{2} \eta^{2} \Delta^{2}+O\left(\Delta^{3}\right)
$$

Neglecting third-order terms and using $\alpha=\sigma$, we obtain

$$
\begin{aligned}
\operatorname{Var}\left(\Delta y_{t}\right) & =\eta^{2} \Delta+\left(c_{1} c_{2}-\frac{1}{2} \eta^{2}\right)\left(\frac{\alpha}{1-\alpha}\right)^{2} \frac{1}{2} \eta^{2} \Delta^{2} \\
& =\eta^{2} \Delta+\frac{\alpha}{1-\alpha}\left(\frac{\alpha}{1-\alpha} \mu+\rho+\frac{1-\tau_{i}}{1+\tau_{k}} \delta+\tau_{a}-\frac{\alpha}{1-\alpha} \frac{1}{2} \eta^{2}\right) \frac{1}{2} \eta^{2} \Delta^{2}
\end{aligned}
$$

It shows that second-order approximations are necessary in order to capture tax effects on macro volatility, which linearized versions would neglect. Table 2 illustrates that these second-order effects indeed can be economically important.

\footnotetext{
${ }^{9}$ For a similar mean-reverting model of the spot rate dynamics, namely the Ornstein-Uhlenbeck process, $d r_{t}=c_{1}\left(c_{2}-r_{t}\right) d t+c_{3} d B_{t}$, the auto-covariance function and the measure is available in closed form. For this linear model, $\operatorname{Var}\left(\int_{t-\Delta}^{t} r_{s} d s\right)$ is proportional to $\operatorname{Var}(r) \equiv \lim _{t \rightarrow \infty} \operatorname{Var}_{0}\left(r_{t}\right)$, and $\operatorname{Var}\left(\int_{t-\Delta}^{t} r_{s} d s\right) \approx \operatorname{Var}(r) \Delta^{2}$ coincides with the second-order Taylor approximation about $\Delta=0$.
} 
Economically speaking, a positive tax on wealth, $\tau_{a}>0$, distorts the consumptionsaving decision. Incentives for capital accumulation will be lower since net capital returns decrease similar to the effect of an increased depreciation rate. Individuals prefer more consumption today instead of deferring it to the future. The non-stochastic steady state value for capital rewards increases (effective capital stock decreases) as less resources are used for capital accumulation. Because from (11) innovations to $r_{t}$ are proportionally to the level of $r_{t}$, it results into a higher variance of capital rewards. As this variance contributes to the propagation component of output volatility, an increase in $\tau_{a}$ finally translates into higher output volatility in (17).

\subsection{Taking the model to the data}

After having studied the qualitative and quantitative effects, we now ask whether tax effects on macro volatility can be established empirically. To this end, we use our explicit solution for the growth rates to formalize our empirical strategy rewriting (12) as

$$
\Delta y_{t} \equiv E\left(\Delta y_{t}\right)+\epsilon_{t}
$$

The residual variable is $\epsilon_{t} \equiv\left(\mu-\frac{1}{2} \eta^{2}\right) \Delta+\sigma\left(\ln C_{t}-\ln C_{t-\Delta}\right)-E\left(\Delta y_{t}\right)+\eta\left(B_{t}-B_{t-\Delta}\right)$, which has mean zero and tax-dependent variance. It simply denotes the deviation of the actual growth rate from its long-run mean, capturing the transitional dynamics of the neoclassical model. If capital rewards are above average (technically if the capital stock is below its non-stochastic steady state), the growth rate is higher than the long-run mean.

From an econometric point of view, we can exploit the fact that $\epsilon_{t}$ is a residual term with zero mean and tax-dependent variance by explicitly modeling (and estimating) an unobserved heteroscedasticity process defining $\theta_{i} \equiv E\left(\Delta y_{i t}\right)$ for country $i$ as follows,

$$
\begin{aligned}
\Delta y_{i t} & =\theta_{i}+\epsilon_{i t}, \quad \text { where } E\left(\epsilon_{i t}\right)=0, \operatorname{Var}\left(\epsilon_{i t}\right)=h_{i t}, \\
h_{i t} & =f \text { (taxes). }
\end{aligned}
$$

Neglecting transitional dynamics in the growth equation, we can analyze the properties of a model where the second rather than the first moment depends on taxes.

\section{Data and estimation strategy}

Our approach to study output volatility patterns is to employ a panel of OECD countries spanning the years 1970 to 2004 . This provides the possibility of generating more accurate predictions for individual observations than time series data alone. If the countries behave similarly conditional on certain variables, as we would expect for incentives through tax 
Figure 1: Comparison of different observed volatility measures for key countries
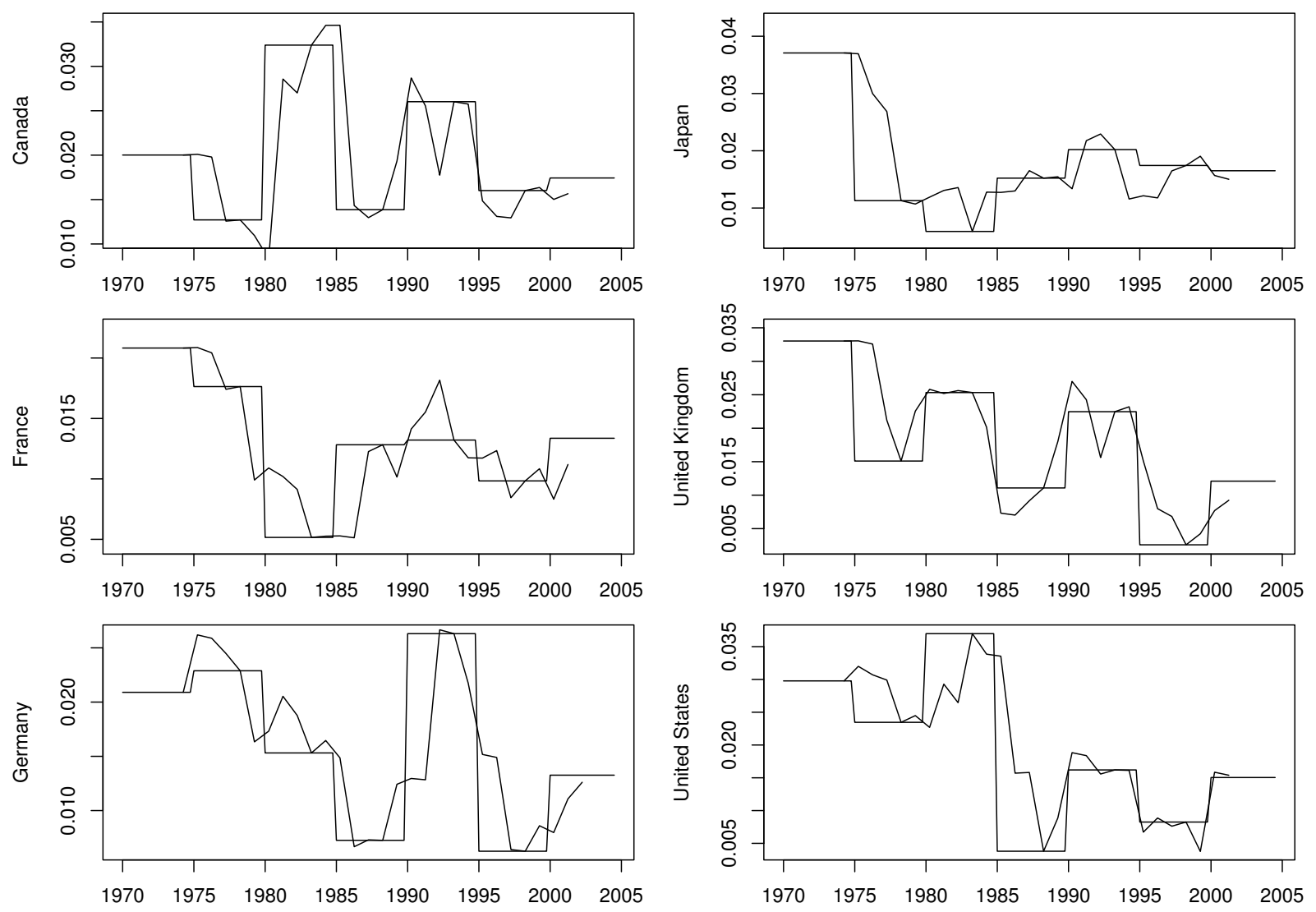

Notes: These figures compare observed volatility measures for key countries starting in 1970 . The first measure results from a fixed-window (five-years) approach gathering the period specific $s d$ of annual growth rates of real GDP per capita, while the second measure is based on five-year rolling $s d$ of annual growth rates of real GDP per capita.

rates, panel data provide the possibility of learning the behavior of a single country by observing the behavior of other countries.

Data. In what follows we use measures of volatility and the effective tax burden at the macro level. There seems to be consensus in the literature on the "great moderation" that a useful measure of macro volatility is the standard deviation $(s d)$ of output growth rates. Our focus is on the $s d$ of annual growth rates of real GDP per capita $(A P C) .{ }^{10}$ The reason for using data at annual frequency is the availability of tax measures.

In order to compute meaningful measures of output volatility, we need to collapse several periods into one observation using fixed windows or using rolling windows. While the first approach throws away information, the latter has quite complicated statistical properties. Nonetheless both are useful for the purpose of illustration, robustness checks,

\footnotetext{
${ }^{10}$ Similar results based on quarter-to-quarter growth rates $(Q G R)$ on four-quarter rolling growth rates $(A G R)$, as well as on HP-filtered cyclical components $(C Y C)$ are provided in a separate appendix.
} 
Table 3: Linking theoretical tax rates to tax ratios

\begin{tabular}{lcccc} 
& $\begin{array}{r}\text { income tax, } \\
\tau_{i}\end{array}$ & $\begin{array}{c}\text { consumption } \\
\operatorname{tax}, \tau_{c}\end{array}$ & $\begin{array}{c}\text { investment } \\
\operatorname{tax}, \tau_{k}\end{array}$ & $\begin{array}{c}\text { tax on wealth, } \\
\tau_{a}\end{array}$ \\
\hline \hline LABOR & $\times$ & & & $\times$ \\
$C A P I T A L$ & $\times$ & & $\times$ & \\
$C O R P$ & $\times$ & & & \\
CONS & & $\times$ &
\end{tabular}

Notes: Based on Mendoza et al.'s (1994) definitions, $L A B O R$ denotes the labor income tax ratio, $C A P I T A L$ is the capital tax ratio (including taxes on property), CORP is the corporate income tax ratio, CONS is the consumption tax ratio. Taxes on investment goods are included only in the Carey and Rabesona (2004) tax ratio.

and are widely used in the profession. For the first approach, we make use of two windows (five-years and ten-years), and gather the mean and the $s d$ of variables starting in 1970. In the latter approach, we use the five-year rolling standard deviation of output growth rates as in Blanchard and Simon (2001). Both measures clearly indicate that output volatility differs substantially over time and across countries (cf. Figure 1).

To measure the average tax burden of a representative household on macro level we choose the approach of Mendoza et al. (1994). ${ }^{11}$ Accordingly, we use four different types of taxes, namely a tax measuring the tax induced cost of dependent labor $(L A B O R)$, i.e., taxes on labor income, security charges and payroll taxes; a tax measuring the cost of capital through taxation $(C A P I T A L)$, i.e., taxes on capital income, on the capital stock as well as on capital transactions; an income tax of corporations (CORP); and a consumption $\operatorname{tax}(C O N S)$, i.e., taxes on goods and services and excise taxes. Most notably, $C A P I T A L$ contains taxes on property, including recurrent taxes on immovable property as well as taxes on financial and capital transactions. ${ }^{12}$ This comprises the inheritance tax which, given an infinite horizon framework, could be interpreted as taxes on wealth rather than taxes on income. To this end, the empirical tax ratios convey the meaning of theoretical tax rates as summarized in Table 3. In that view, LABOR and CORP are pure taxes on income, whereas CAPITAL measures the tax burden associated with capital income, capital flows and the capital stock.

Figure 2 shows the time paths of tax ratios and five-year $s d$ of output growth rates for major countries from 1970, illustrating the time dimension of our panel. Note that abrupt changes of CAPITAL due to major tax reforms, which coincide with breaks in output volatility in the 1980s and the 1990s, can be observed for the UK and the US,

\footnotetext{
${ }^{11}$ We also used modifications of Carey and Rabesona (2004) for effective tax rates with similar results.

${ }^{12}$ Ideally the tax on the capital stock should be separated from the tax on capital income as effects on volatility are different. However due to data availability we follow the common practice and allocate these taxes to the cost of capital (CAPITAL).
} 
Figure 2: Tax ratios and observed volatility for key countries
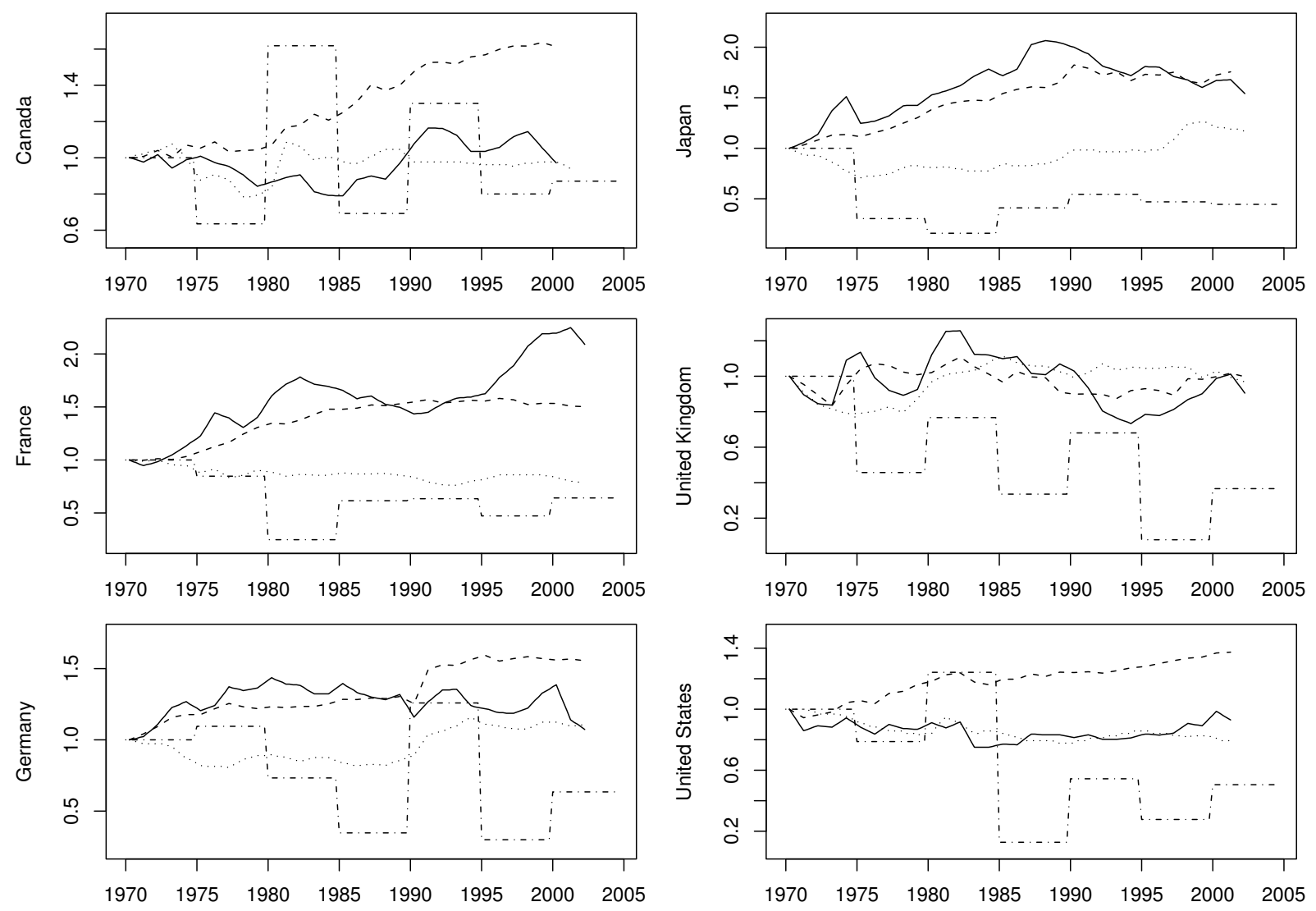

Notes: These figures illustrate the time paths of tax ratios for capital (CAPITAL, solid), labor income ( $L A B O R$, dashed), and consumption (CONS, dotted) together with the $s d$ of annual growth rates of real GDP per capita (dotdashed) using the fixed-window (five-years) approach (cf. Figure 1, dot-dashed) for key countries $(1970=1)$.

respectively. For illustration, the UK capital transfer tax (replaced by the inheritance tax in 1986) was cut from 75 percent in 1984 to 40 percent in 1988 and accompanied by an increase of the threshold from $25,000 £$ in 1980 to $200,000 £$ in 1995 . As a matter of fact, the contribution of property tax revenues to CAPITAL in the UK declined substantially from 30.2 percentage points in 1981 to 13.8 percentage points in 1992. Similarly, there is considerable heterogeneity in the cross-sectional dimension as reported in scatter plots of output volatility versus tax rates (Appendix A.4, Figures A.1 and A.3), respectively. Though some regularities in the data, no clear cut conclusion is drawn from the plots.

Other controls in volatility estimations include the mean per capita output growth rate $(G R O W)$, the mean and $s d$ of the inflation rate (INFL, INFLSD), the mean and $s d$ of government consumption as a share of output (GGDP, GGDPSD), the degree of openness measured by the ratio of exports plus imports to output (OPEN), the $s d$ of real effective exchange rates $(X R S D)$, and the allocation of total credit to the private 
sector as percentage of GDP measuring financial development $(P R I V Y) .{ }^{13}$

Estimation strategy. We are now prepared to address our empirical question: Conditional on other controls, does output volatility vary systematically with tax rates? To this end, we jointly estimate the parameters of the following system,

$$
\begin{aligned}
\Delta y_{i t} & =\theta_{i}+\epsilon_{i t}, \quad \text { where } \quad \epsilon_{i t} \sim \mathcal{N}\left(0, \sigma_{i t}^{2}\right), \\
\log \left(\sigma_{i t}\right) & =\alpha_{i}+\lambda_{t}+\beta^{\prime} x_{i t}+\gamma^{\prime} z_{i t} .
\end{aligned}
$$

$\Delta y_{i t}$ is the output per capita growth rate for country $i=1, \ldots, N$ and $t=1, \ldots, T$, expressed in log differences, $\theta_{i}$ is a country-specific mean and $\sigma_{i t}$ denotes the $s d$ of the residuals $\epsilon_{i t}$. Our primary focus is on the unobserved volatility process (19b) which models $\log \left(\sigma_{i t}\right)$ as a linear function of country- and time-specific effects, $\alpha_{i}+\lambda_{t}$, as well as tax rates, $x_{i t}$, and other controls, $z_{i t}$. This specification ensures that $\sigma_{i t}$ is positive. Another convenient property is that the parameters are interpreted as semi-elasticities.

Two caveats are important. First, our results are based on asymptotic properties, hence the cross sectional dimension should be more important than the time-dimension. For this reason, we do not account for dynamics in the mean equation but allow for a country specific long-run mean. Second, we assume that the error terms are independently distributed which again only holds asymptotically. Assuming that variables are close to steady-state values and shocks are small, helps us to address both caveats. Moreover, we check the robustness of our results by using different estimation strategies below.

Our system (19) is nested in an autoregressive conditional heteroscedasticity (ARCH) model. It extends the econometric approach in Ramey and Ramey (1995), allowing for more flexibility in the conditional variance equation by including additional controls and time dummies. The parameter vector $\vartheta \equiv(\theta, \sigma, \alpha, \lambda, \beta, \gamma)$ is estimated jointly using maximum likelihood (ML) treating the variances as parameters. It is straightforward to show that the log-likelihood function reads apart from a constant

$$
\ell(\vartheta)_{N T}=-\sum_{t=1}^{T} \sum_{i=1}^{N} \log \left(\sigma_{i t}\right)-\frac{1}{2} \sum_{t=1}^{T} \sum_{i=1}^{N}\left(\epsilon_{i t} / \sigma_{i t}\right)^{2} .
$$

Under sufficient regularity conditions, the maximum likelihood estimator is consistent and asymptotic normal. We employ this result to obtain asymptotic standard errors based on the information matrix using the outer product estimate.

For a quick look at the data, we begin estimating the following econometric model,

$$
\log \left(\sigma_{i t}\right)=\alpha_{i}+\lambda_{t}+\beta^{\prime} x_{i t}+\gamma^{\prime} z_{i t}+u_{i t},
$$

\footnotetext{
${ }^{13}$ There is now a large literature on volatility estimation including Blanchard and Simon (2001), Denizer et al. (2002), Lensink and Scholtens (2004), Cecchetti et al. (2006), and Jaimovich and Siu (2009).
} 
using observed volatility measures, $\sigma_{i t}$, denoting the $s d$ of annual output growth rates per capita in the fixed window $t=1, \ldots, T$, where $T=7$ (five-years) or $T=4$ (ten-years), for country $i=1, \ldots, N{ }^{14}$ Similar to $(19 \mathrm{~b}), \log \left(\sigma_{i t}\right)$ is modeled as a function of country- and time-specific effects, $\alpha_{i}+\lambda_{t}$, taxes, $x_{i t}$, other controls, $z_{i t}$, and an uncorrelated error term with mean zero and equal variance, $u_{i t}$. Note that (21) emphasizes the cross-sectional dimension relative to the time-dimension, and thus indeed is suitable for the study of asymptotic properties in the data. This approach therefore is complementary to our likelihood-based approach. We obtain the parameter estimates using the least square dummy variable (LSDV) methodology. To avoid that results are driven by few outliers, we also use iterated weighted least squares (IWLS) estimation. ${ }^{15}$

So far, we treated our variables as $I(0)$. However, taxes and/or other controls may be (locally) non-stationary. If taxes and output volatility are $I(1)$, our results may be either spurious or superconsistent. The latter is true for a cointegrating relationship. A formal test of cointegration cannot be applied to unobserved variables. Nevertheless, to strengthen our result of a long-run relationship between taxes and output volatility, we extend our analysis to a dynamic approach, assuming variables to be at least $I(1)$,

$$
\begin{aligned}
\Delta y_{i t} & =\theta_{i}+\epsilon_{i t}, \quad \text { where } \epsilon_{i t} \sim \mathcal{N}\left(0, \sigma_{i t}^{2}\right), \\
\Delta \log \left(\sigma_{i t}\right) & =\alpha_{i}+\lambda_{t-1}+\beta^{\prime} x_{i, t-1}+\gamma^{\prime} z_{i, t-1}+\rho \log \left(\sigma_{i, t-1}\right),
\end{aligned}
$$

for given country-specific initial conditions $\sigma_{i, 0}$. Obviously, the estimated parameters are not directly comparable with the static approach (19b) as long as $\rho \neq-1$. Note that this approach closely follows the cointegration idea: Suppose taxes and output volatility are not cointegrated. In order to balance the time series property that the left-hand side of (22b) is stationary, neither $\beta, \gamma$ or $\rho$ can be different from zero to obtain stationarity on the right-hand side. ${ }^{16}$ Observe that the system (22) is nested in an generalized autoregressive conditional heteroscedasticity (GARCH) model.

As a quick check, we estimate an error correction specification similar to (22b),

$$
\Delta \log \left(\sigma_{i t}\right)=\alpha_{i}+\lambda_{t-1}+\beta^{\prime} x_{i, t-1}+\gamma^{\prime} z_{i, t-1}+\rho \log \left(\sigma_{i, t-1}\right)+v_{i t},
$$

where $\sigma_{i t}$ denotes the observed $s d$ of annual output growth rates per capita in the five-year fixed-window $t$ for country $i$, and $v_{i t}$ again is an uncorrelated error term with mean zero

\footnotetext{
${ }^{14}$ See Blanchard and Simon (2001) and Jaimovich and Siu (2009) for similar specifications. One concern in this specification is that the results might be spurious. As the time horizon using the fixed-window specification is very short, this is not as problematic as using rolling-windows.

${ }^{15}$ It is well known that the least squares estimator is particularly sensitive to small numbers of atypical data points when the sample size is small or moderate. Using regression diagnostics for influential data points (leave-one-out deletion) suggests that a small number of observations have potentially large effects.

${ }^{16}$ We are not aware of research on cointegration within the conditional variance equation. According to the standard cointegration principle, however, one should add an error term to equation (22b) as in (23). This would lead to a stochastic volatility model which is an interesting path for future research.
} 
and equal variance. A formal investigation of no cointegration amounts to testing the null hypothesis of the parameters in front of the controls to be zero (e.g., Banerjee 1999). One caveat is the well known bias of the coefficients in dynamic panels in the presence of individual effects (Nickell 1981). Various techniques have been proposed in the literature. Most approaches have important drawbacks as they may require additional decisions regarding which and how many instruments to use or the performance may depend on model-specific properties (see Bun and Carree 2005). We address this caveat by using Bun and Carree's (2005) bias-correction for the LSDV estimator.

\section{Empirical results}

This section holds the estimation results. Following our estimation strategy, we use observed volatility measures to get a general idea about effects present in the data. We then fully exploit the panel structure by treating unobserved variances as parameters.

\subsection{Observed variances}

Static panel estimation. A quick answer to our empirical question is in Table 4, which gives estimates for the semi-elasticities of various controls on observed output growth volatility (percentage change of $\sigma_{i t}$ given a percentage point increase of the control) for our model in (21). It shows that output volatility indeed can be explained by various fundamentals capturing roughly half of the variability of our volatility measure. Our key parameter vector of interest is $\beta$, which links our empirical tax ratios to volatility.

We find quite robust empirical evidence for tax effects on output volatility in line with our theoretical results (compare with Tables 2 and 3). The estimates in Table 4 show that our results are similar for different estimators and window spans. To summarize, effects of taxes on corporate income $(C O R P)$ and on labor income $(L A B O R)$ are statistically significant and negative. Holding constant other variables, an increase of $L A B O R$ by one percentage point decreases output volatility by five to eight percent. The capital tax $(C A P I T A L)$ is positively related, and the consumption tax $(C O N S)$ has no clear effect. Estimates of the other controls are in line with the literature. The estimated coefficient for mean growth $(G R O W)$ confirms a significant and negative link with output volatility for the ten-year window. Measures of openness $(O P E N)$, exchange rate volatility $(X R S D)$, government expenditures volatility $(G G D P S D)$ and inflation rate volatility (INFLSD) are positively related. Somewhat controversial, we find a negative effect of the mean inflation rate $(I N F L)$. Denizer et al. (2002) find no statistically significant effect, while a positive link is found in Lensink and Scholtens (2004). The coefficient for government expenditures $(G G D P)$ indicates an anti-cyclical policy but is insignificant in 
Table 4: Static panel estimation, observed volatility measures (fixed-windows)

\begin{tabular}{|c|c|c|c|c|c|}
\hline \multicolumn{2}{|l|}{$O E C D$} & $\begin{array}{c}\text { LSDV } \\
\text { (five-year) } \\
\end{array}$ & $\begin{array}{c}\begin{array}{c}\text { IWLS } \\
\text { (five-year) }\end{array} \\
\end{array}$ & $\begin{array}{c}\begin{array}{c}\text { LSDV } \\
\text { (ten-year) }\end{array} \\
\end{array}$ & $\begin{array}{c}\begin{array}{c}\text { IWLS } \\
\text { (ten-year) }\end{array} \\
\end{array}$ \\
\hline$L A B O R_{i t}$ & $\beta_{1}$ & $-8.28(2.03)^{* * *}$ & $-7.83(1.83)^{* * *}$ & $-5.72(1.92)^{* *}$ & $-5.43(1.94)^{* *}$ \\
\hline$C A P I T A L_{i t}$ & $\beta_{2}$ & $6.24(1.46)^{* * *}$ & $5.01(1.43)^{* *}$ & $5.54(1.43)^{* * *}$ & $4.55(1.42)^{* *}$ \\
\hline$C O N S_{i t}$ & $\beta_{3}$ & $5.89(2.40)^{*}$ & $4.79(2.74)$ & $-0.41(2.68)$ & $-0.48(2.85)$ \\
\hline$C O R P_{i t}$ & $\beta_{4}$ & $-3.83(0.90)^{* * *}$ & $-3.15(0.92)^{* * *}$ & $-2.89(1.08)^{* *}$ & $-2.28(0.98)^{*}$ \\
\hline$G R O W_{i t}$ & $\gamma_{1}$ & $-8.18(5.02)$ & $-7.37(4.89)$ & $-29.77(8.23)^{* * *}$ & $-21.30(7.49)^{* *}$ \\
\hline$P R I V Y_{i t}$ & $\gamma_{2}$ & $-0.30(0.40)$ & $-0.31(0.41)$ & $-0.47(0.34)$ & $-0.36(0.41)$ \\
\hline$I N F L_{i t}$ & $\gamma_{3}$ & $-5.70(2.00)^{* *}$ & $-6.84(2.05)^{* * *}$ & $-4.86(2.36)^{*}$ & $-3.71(2.70)$ \\
\hline$I N F L S D_{i t}$ & $\gamma_{4}$ & $10.24(3.83)^{* *}$ & $10.72(3.35)^{* *}$ & $6.45(2.78)^{*}$ & $5.93(3.46)$ \\
\hline$O P E N_{i t}$ & $\gamma_{5}$ & $2.61(0.76)^{* * *}$ & $2.43(0.75)^{* *}$ & $1.73(0.58)^{* *}$ & $1.21(0.69)$ \\
\hline$X R S D_{i t}$ & $\gamma_{6}$ & $1.30(2.08)$ & $3.13(1.90) \cdot$ & $2.90(2.97)$ & $3.61(2.71)$ \\
\hline$G G D P_{i t}$ & $\gamma_{7}$ & $-2.46(3.64)$ & $-1.45(3.73)$ & $-5.09(3.38)$ & $-2.59(3.92)$ \\
\hline$G G D P S D_{i t}$ & $\gamma_{8}$ & $48.84(14.52)^{* *}$ & $39.33(14.92)^{*}$ & $-4.01(11.33)$ & $-7.82(11.30)$ \\
\hline Degrees of free & lom & 85 & 85 & 38 & 38 \\
\hline Adjusted $R$-squ & red & 0.43 & & 0.48 & \\
\hline$F$-stat & stic & 3.53 & & 2.95 & \\
\hline Country fixed effects & $\alpha_{i}$ & yes & yes & yes & yes \\
\hline Time fixed effects & $\lambda_{t}$ & yes & yes & yes & yes \\
\hline
\end{tabular}

Signif. codes: $0^{(* * *)} 0.001^{(* *)} 0.01^{(*)} 0.05^{6,} 0.1$

Notes: This table reports the semi-elasticities of the fixed-effects model (21) using the least square dummy variable approach (LSDV) and iterated weighed least squares estimation (IWLS), explaining the $s d$ of annual growth rates of real GDP per capita. Standard errors of White's heteroscedasticity-consistent covariance matrix estimators (HCCME) in the LSDV approach, and of $R=4999$ model-based bootstrap replicates using the adjusted percentile method for IWLS estimates are in parentheses.

the specifications shown above. Similarly, the effect of financial development (PRIVY) is not robust. Figures A.2 and A.4 plot taxes against estimated volatility, after removing the effects of the other variables (cf. Appendix A.4).

Dynamic panel estimation. To avoid a spurious association, we check our results estimating (23). Collecting terms gives the endogenous variable $\log \left(\sigma_{i t}\right)$ as a function of its lagged value and other controls. As a result, we find only a small bias. Table 5 gives the estimate of $\rho$ between $-1.15(0.11)$ and $-1.32(0.13)$ with biased corrected standard deviation in parentheses. A formal test of no cointegration, $\rho=0$, would be rejected at any conventional significance level. An important caveat is that a time dimension of $T=6$ is very short for residual-based tests of no cointegration (see Pedroni 2004). Our bottom line is that tax effects remain statistically significant in the dynamic specification suggesting that our results are not spurious. 
Table 5: Dynamic panel estimation, observed variances (fixed-windows)

\begin{tabular}{|c|c|c|c|c|c|}
\hline \multicolumn{2}{|l|}{$O E C D$} & $\begin{array}{l}\text { LSDV-BC (i) } \\
\text { (five-year) }\end{array}$ & $\begin{array}{l}\text { LSDV-BC (ii) } \\
\text { (five-year) }\end{array}$ & $\begin{array}{c}\text { LSDV-BC (iii) } \\
\text { (five-year) }\end{array}$ & $\begin{array}{c}\text { LSDV-BC (iv) } \\
\text { (five-year) }\end{array}$ \\
\hline$L A B O R_{i, t-1}$ & $\beta_{1}$ & $-3.37(2.24)$ & $-5.93(3.35)$ & $-8.24(1.95)^{* * *}$ & $-7.44(3.14)^{*}$ \\
\hline$C A P I T A L_{i, t-1}$ & $\beta_{2}$ & $5.78(1.94)^{* *}$ & $7.40(2.58)$ ** & $6.41(2.03)^{* *}$ & $8.42(2.54)^{* *}$ \\
\hline$C O N S_{i, t-1}$ & $\beta_{3}$ & $1.66(3.21)$ & $2.00(4.85)$ & $0.22(2.99)$ & $5.14(4.34)$ \\
\hline$C O R P_{i, t-1}$ & $\beta_{4}$ & $-2.49(1.30)$ & $-2.94(1.66)$ & $-2.97(1.37)^{*}$ & $-3.55(1.64)^{*}$ \\
\hline$G R O W_{i, t-1}$ & $\gamma_{1}$ & & $-3.04(7.82)$ & & $11.08(6.68)$ \\
\hline$P R I V Y_{i, t-1}$ & $\gamma_{2}$ & & $0.20(0.76)$ & & $0.22(0.68)$ \\
\hline$I N F L_{i, t-1}$ & $\gamma_{3}$ & & $2.61(3.25)$ & & $3.79(3.01)$ \\
\hline$I N F L S D_{i, t-1}$ & $\gamma_{4}$ & & $-3.23(5.85)$ & & $-1.28(5.30)$ \\
\hline$O P E N_{i, t-1}$ & $\gamma_{5}$ & & $0.79(1.54)$ & & $-0.04(1.30)$ \\
\hline$X R S D_{i, t-1}$ & $\gamma_{6}$ & & $-2.21(3.08)$ & & $1.09(2.98)$ \\
\hline$G G D P_{i, t-1}$ & $\gamma_{7}$ & & $1.79(6.25)$ & & $-2.39(5.57)$ \\
\hline$G G D P S D_{i, t-1}$ & $\gamma_{8}$ & & $28.63(24.62)$ & & $49.37(23.74)^{*}$ \\
\hline$\sigma_{i, t-1}$ & $1+\rho$ & $-0.15(0.11)$ & $-0.21(0.15)$ & $-0.23(0.13)^{*}$ & $-0.32(0.13)^{*}$ \\
\hline Country fixed effects & $\alpha_{i}$ & yes & yes & yes & yes \\
\hline Time fixed effects & $\lambda_{t-1}$ & yes & yes & no & no \\
\hline \multicolumn{2}{|c|}{ Degrees of freedom } & 89 & 68 & 94 & 73 \\
\hline \multicolumn{2}{|c|}{ Adjusted $R$-squared } & 0.26 & 0.19 & 0.11 & 0.13 \\
\hline \multicolumn{2}{|c|}{$F$-statistic } & 2.43 & 1.67 & 1.63 & 1.51 \\
\hline
\end{tabular}

Signif. codes: $0^{(* * *)} 0.001^{(* *}, 0.01^{(*,} 0.05^{6,} 0.1$

Notes: This table reports the semi-elasticities of the dynamic model specification (23) using the least square dummy variable approach (LSDV) with the proposed bias correction for dynamic panel models of Bun and Carree (2005), explaining the $s d$ of annual growth rates of real GDP per capita. Biased-corrected standard errors are in parentheses.

\subsection{Treating variances as parameters}

We further examine the relationship between output growth volatility and various control variables including taxes by fully taking advantage of the panel structure of our data set.

Static panel estimation. We start estimating (19) without additional controls, then we proceed using a similar specification as in Table 4. However, we need to change the nature of the variables included in the $z_{i t}$ vector as follows. To obtain volatility measures of the inflation rate, government expenditures, and the real effective exchange rate, respectively, we follow Ramey and Ramey and use the innovations to country-specific forecasting equations which include a constant, linear and quadratic time trends, and specific controls. Instead of squared residuals we use absolute values. For the innovations to the inflation forecast (INFLFI) we make use of a Phillips curve based on measures of aggregate activity (see Stock and Watson 1999). We use two lags of HP-filtered cyclical component of real GDP per capita and two lags of the inflation rate in addition to the deterministic trends. Shocks to the forecast of government-spending growth (DGFI) are based on two lags of log real GDP per capita and log government spending per capita; 
Table 6: Static panel estimation, treating variances as parameters

\begin{tabular}{|c|c|c|c|c|c|}
\hline \multicolumn{2}{|l|}{$O E C D$} & MLE (i) & MLE (ii) & MLE (iii) & MLE (iv) \\
\hline$L A B O R_{i, t-1}$ & $\beta_{1}$ & $-4.23(1.52)^{* *}$ & $-4.76(2.35)^{*}$ & $-6.15(1.18)^{* * *}$ & $-4.80(1.87)^{*}$ \\
\hline$C A P I T A L_{i, t-1}$ & $\beta_{2}$ & $4.17(1.29)^{* *}$ & $6.03(1.92)^{* *}$ & $4.04(1.21)^{* * *}$ & $6.83(1.79)^{* * *}$ \\
\hline$C O N S_{i, t-1}$ & $\beta_{3}$ & $2.25(1.91)$ & $3.31(2.87)$ & $0.41(1.66)$ & $2.80(2.50)$ \\
\hline$C O R P_{i, t-1}$ & $\beta_{4}$ & $-1.78(0.65)^{* *}$ & $-2.54(0.96)^{* *}$ & $-1.69(0.61)^{* *}$ & $-2.74(0.89)^{* *}$ \\
\hline$P R I V Y_{i, t-1}$ & $\gamma_{1}$ & & $0.11(0.55)$ & & $0.09(0.44)$ \\
\hline$I N F L_{i, t-1}$ & $\gamma_{2}$ & & $3.14(1.77) \cdot$ & & $3.74(1.53)^{*}$ \\
\hline$I N F L I_{i, t-1}$ & $\gamma_{3}$ & & $9.21(3.72)^{*}$ & & $9.85(3.68)^{* *}$ \\
\hline$G G D P_{i, t-1}$ & $\gamma_{4}$ & & $0.89(4.35)$ & & $-1.36(4.09)$ \\
\hline$D G F I_{i, t-1}$ & $\gamma_{5}$ & & $0.02(0.04)$ & & $0.02(0.04)$ \\
\hline$X R F I_{i, t-1}$ & $\gamma_{6}$ & & $2.58(1.04)^{*}$ & & $2.42(0.97)^{*}$ \\
\hline Degrees of free & om & 584 & 452 & 589 & 457 \\
\hline Log-likelih & pod & 1605.6 & 1326.4 & 1594.0 & 1320.5 \\
\hline Country fixed effects & $\alpha_{i}$ & yes & yes & yes & yes \\
\hline Time fixed effects & $\lambda_{t}$ & yes & yes & no & no \\
\hline
\end{tabular}

Notes: This table reports the semi-elasticities of the joint estimation of (19) using maximum likelihood, explaining the conditional $s d$ of annual growth rates of real GDP per capita. Asymptotic standard errors are in parentheses.

the forecast for the exchange rate $(X R F I)$ is based on two autoregressive lags. ${ }^{17}$

Observing a break in volatility every year does not seem plausible. Nevertheless, there seems to be consensus that breaks in volatility are observed over time. We allow for timespecific breaks in the conditional variance using time dummies based on Stock and Watson (2005), such that major breaks in volatility and other events occurring broadly across countries are taken into account. Clearly, the assumption that these breaks occurred at the same time for all countries is strong. ${ }^{18}$ It seems reasonable, however, to assume that effects of important events spread over to other countries. Summarizing, we include $D=5$ time dummies, for the period until 1979 (through the breaks around 1980 in the UK 1979:4-82:1 and Italy 1979:3-82:4), for 1980-83 (until the break around 1984 in the US 1982:4-85:3), for 1984-86 (until the stock market crash in 1987), for 1987-1992 (ending with breaks around 1993 in Germany 1992:3-95:2 and Canada 1990:4-93:1), and for 1993-2000 (new economy bubble burst).

To avoid endogeneity problems arising with contemporaneous explanatory variables, we use one-period lagged values. Comparing the results in Table 6 with those obtained from observed variances in Table 4, we find striking similarities of tax effects on output volatility, while using completely different estimation methods. Hence, taxes on labor

\footnotetext{
${ }^{17}$ We exclude $O P E N$ which turned out to be insignificant and uninformative for the whole estimation approach, while its effect seems to be fully captured by $X R F I$. Moreover, for technical reasons we have to drop $G R O W$ as an explanatory variable. We refer to the growth-volatility link in the next section.

${ }^{18}$ Note that Stock and Watson (2005) only test for a single break date. Multiple break dates are e.g. in Cecchetti et al. (2006) suggesting that our dummies capture breaks occurring broadly across countries.
} 
income $(L A B O R)$ and corporate income $(C O R P)$ decrease volatility, while the tax on capital $(C A P I T A L)$ is associated with higher volatility. Even the order of magnitude for tax rates is roughly comparable to that of initial estimates obtained before. For example, a percentage point increase in $C A P I T A L$ increases output volatility roughly by five percent, which again is substantially higher than the theoretical semi-elasticities just under one percent (cf. Table 2). As already mentioned, due to the narrow structure of our neoclassical model without rigidities and with constant labor supply, this result is not surprising. A more elaborate model is needed to match these empirical findings. Given our theoretical results, tax effects on labor supply and its variability would not come as a surprise. Recent research traces the declining output volatility in the US, e.g., to less volatile labor input (Stiroh 2009). ${ }^{19}$ Beside tax effects, other controls that significantly contribute to output volatility are innovations to the forecast of the real effective exchange rate $(X R F I)$, innovations to the inflation forecast (INFLFI), and the inflation rate $(I N F L)$. Note that the latter result resolves the controversial negative effect obtained by our initial estimates for INFL. A monetary authority focusing on a stable and low inflation rate removes output volatility, a result which is confirmed by the forecasting equations: INFL significantly increases INFLFI for most countries (see also Ball 1992). Financial development is not statistically significant. In contrast to Ramey and Ramey, the innovations to government expenditures are not significant. ${ }^{20}$

For illustration, Figure 3 shows the estimated volatility patterns for key countries. Overall, the time paths and cross country patterns are captured by the model, with some differences in the explanatory power of control variables. While taxes account for most of the variation in the UK and France (not shown), the time path for the other countries are captured only after including additional control variables. The inclusion of time-specific dummies improves the fit, but does not change the overall pattern.

Dynamic panel estimation. When estimating (22) jointly, using the panel structure of our data more efficiently, we address the issue of a 'cointegrating relationship'. Note that our conclusions will not depend on time-fixed effects which may account for the non-stationarity to some extent. Conversely, especially for the case without time-specific effects the estimated values should not be different from zero unless there was cointegration. To start with, we need pre-sample estimates for $\sigma_{i t}^{2}$ for $t \leq 0$. As a natural choice, we follow Bollerslev (1986) and use country-specific sample analogues $\sigma_{i, 0}^{2}=T^{-1} \sum_{t} \epsilon_{i t}^{2}$.

\footnotetext{
${ }^{19}$ Bilbiie et al. (2008) stress a negative correlation of output volatility and 'asset market participation'. As already mentioned, CAPITAL includes taxes on financial and capital transaction, suggesting a negative correlation: a lower tax may increase participation in asset markets with lower output volatility.

${ }^{20}$ Contemporaneous estimates suggest that $I N F L$ and $G G D P$ significantly contribute to output volatility. We also experimented with the exclusion of $G G D P$ and $I N F L$ as their lagged values are included in the forecasting equations; however, this does not change the results.
} 
Figure 3: Static panel, observed vs. estimated volatility for key countries, model (ii)
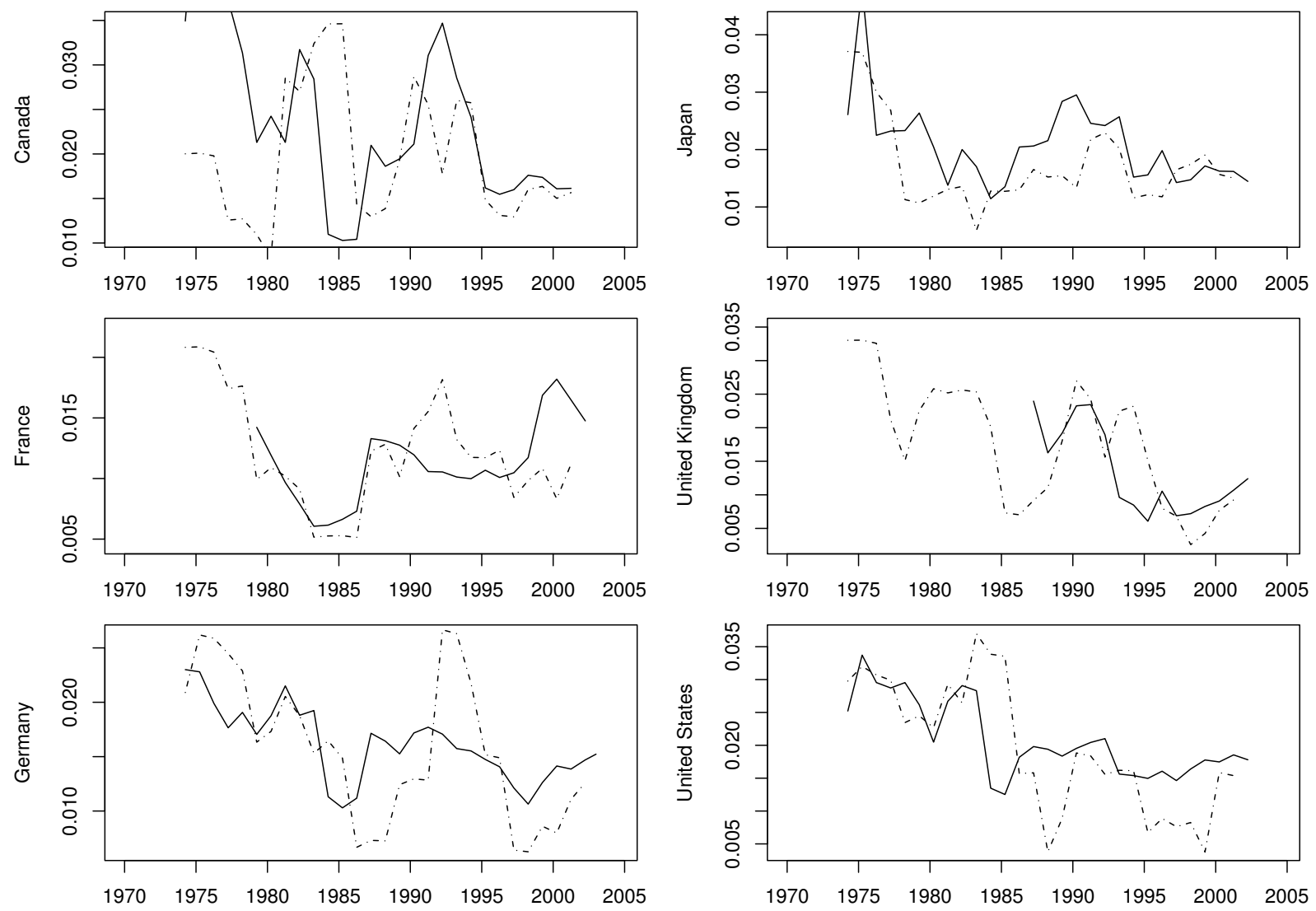

Notes: These figures plot estimated conditional $s d$ (solid) and observed five-year rolling $s d$ (dot-dashed) of annual growth rates of real GDP per capita for key countries starting in 1970 (cf. Table 6, model (ii)).

Our estimated parameters are confirmative of a long-run relationship between taxes and output volatility: the lagged endogenous parameter in the dynamic specification, $1+\rho$, is virtually zero when including time-specific effects, which implies that the key parameter $\rho$ is estimated roughly -0.95 (0.09) with asymptotic standard errors in parenthesis (see Table 7). Without the additional time dummies, the estimated value of $\rho$ lies between $0.21-1=-0.79(0.07)$ and $0.31-1=-0.69(0.08)$ which is significantly different from zero. Other controls suggest only the measure of inflation rate variability (INFLFI) as a potential variable for a cointegrating relationship with output volatility. To compare the order of magnitude to the static approach (see Table 6), we need to scale the estimates for model (ii) and model (iv) by a factor of 1.3 and 1.5 as implied by (22b), respectively, which gives similar point estimates for the semi-elasticities. For example, the parameters linking output volatility and tax rates remain significantly different from zero for $L A B O R$ with an associated long-run semi-elasticity of $-2.82 /(1-0.21)=-3.6$, 
Table 7: Dynamic panel estimation, treating variances as parameters

\begin{tabular}{|c|c|c|c|c|c|}
\hline \multicolumn{2}{|l|}{$O E C D$} & \multirow{2}{*}{$\frac{\text { MLE (i) }}{-1.47(2.17)}$} & MLE (ii) & MLE (iii) & MLE (iv) \\
\hline$L A B O R_{i, t-1}$ & $\beta_{1}$ & & $-2.82(1.34)^{*}$ & $-2.78(0.90)^{* *}$ & $-2.97(1.05)^{* *}$ \\
\hline$C A P I T A L_{i, t-1}$ & $\beta_{2}$ & $3.96(2.00)^{*}$ & $4.72(1.46)^{* *}$ & $2.33(0.84)^{* *}$ & $2.10(0.86)^{*}$ \\
\hline$C O N S_{i, t-1}$ & $\beta_{3}$ & $4.82(2.72)$ & $2.63(1.76)$ & $1.70(1.12)$ & $0.92(0.84)$ \\
\hline$C O R P_{i, t-1}$ & $\beta_{4}$ & $-1.46(1.05)$ & $-2.06(0.75)^{* *}$ & $-1.24(0.51)^{*}$ & $-1.25(0.49)^{*}$ \\
\hline$P R I V Y_{i, t-1}$ & $\gamma_{1}$ & $0.53(0.50)$ & $0.03(0.28)$ & & \\
\hline$I N F L_{i, t-1}$ & $\gamma_{2}$ & $0.90(1.84)$ & $1.85(1.22)$ & & \\
\hline$I N F L F I_{i, t-1}$ & $\gamma_{3}$ & $8.73(3.86)^{*}$ & $9.97(3.52)^{* *}$ & $10.43(2.84)^{* * *}$ & \\
\hline$G G D P_{i, t-1}$ & $\gamma_{4}$ & $-3.99(4.11)$ & $-3.26(2.53)$ & & \\
\hline$D G F I_{i, t-1}$ & $\gamma_{5}$ & $0.02(0.04)$ & $0.05(0.04)$ & $0.05(0.03)$ & \\
\hline$X R F I_{i, t-1}$ & $\gamma_{6}$ & $1.95(1.14)$. & $1.44(1.07)$ & $1.83(0.98) \cdot$ & \\
\hline$\sigma_{i, t-1}$ & $1+\rho$ & $0.05(0.09)$ & $0.21(0.07)^{* *}$ & $0.26(0.06)^{* * *}$ & $0.31(0.08)^{* * *}$ \\
\hline Country fixed effects & $\alpha_{i}$ & yes & yes & yes & yes \\
\hline Time fixed effects & $\lambda_{t-1}$ & yes & no & no & no \\
\hline \multirow{2}{*}{\multicolumn{2}{|c|}{ Degrees of freedom }} & 451 & 456 & 534 & 588 \\
\hline & & 1337.8 & 1323.8 & 1496.1 & 1598.1 \\
\hline
\end{tabular}

Signif. codes: $0^{(* * *)} 0.001^{(* *}, 0.01^{(*)} 0.05^{* \cdot} 0.1$

Notes: This table reports the semi-elasticities of the joint estimation of (19) using maximum likelihood, explaining the conditional $s d$ of annual growth rates of real GDP per capita. Asymptotic standard errors are in parentheses.

for CAPITAL with $4.72 /(1-0.21)=6.0$, and for CORP with a semi-elasticity of $-2.6 /(1-0.21)=-3.3$ (referring to model (ii) of Table 7 ).

\subsection{The link between volatility and growth}

In a seminal paper, Ramey and Ramey (1995) study the link between volatility and growth. Their basic econometric framework is nested in a generalized autoregressive conditional heteroscedasticity-in-mean (GARCH-M) model. In general the GARCH-M model has a drawback as no sufficient conditions for consistency and asymptotic normality are yet known. Following common practice, we assume that the maximum likelihood estimator is consistent and asymptotic normal (see Nelson 1991).

To address the empirical link between volatility and growth, we jointly estimate the following system using maximum likelihood (cf. Ramey and Ramey 1995, p.1141),

$$
\begin{aligned}
\Delta y_{i t} & =\theta_{i}+\nu \sigma_{i t}+\epsilon_{i t}, \quad \text { where } \quad \epsilon_{i t} \sim \mathcal{N}\left(0, \sigma_{i t}^{2}\right) \\
\log \left(\sigma_{i t}\right) & =\alpha_{i}+\lambda_{t}+\beta^{\prime} x_{i t}+\gamma^{\prime} z_{i t}
\end{aligned}
$$

where $\Delta y_{i t}$ is the output per capita growth rate for country $i$ in year $t$, expressed as log difference; $\sigma_{i t}$ is the $s d$ of the residuals $\epsilon_{i t}$; whereas $\theta_{i}$ allows for country-specific effects in the growth equation (24a), and $\alpha_{i}+\lambda_{t}$ are country- and time-specific effects in the 
Table 8: Static panel estimation, the link between volatility and growth

\begin{tabular}{|c|c|c|c|c|c|c|}
\hline$O E C D$ & & MLE (i) & & MLE (ii) & MLE (iii) & MLE (iv) \\
\hline$L A B O R_{i, t-1}$ & $\beta_{1}$ & $-1.34(1.22)$ & & $-3.8900(1.20)^{* *}$ & $-3.96(1.44)^{* *}$ & \\
\hline$C A P I T A L_{i, t-1}$ & $\beta_{2}$ & $3.33(1.05)$ & $* *$ & $3.6400(1.07)^{* * *}$ & $4.32(1.20)^{* * *}$ & \\
\hline$C O N S_{i, t-1}$ & $\beta_{3}$ & $1.40(1.45)$ & & $-0.1300(1.42)$ & $1.72(1.81)$ & \\
\hline$C O R P_{i, t-1}$ & $\beta_{4}$ & $-1.43(0.49)$ & $* *$ & $-1.4800(0.53)^{* *}$ & $-1.77(0.58)^{* *}$ & \\
\hline$P R I V Y_{i, t-1}$ & $\gamma_{1}$ & & & & & \\
\hline$I N F L_{i, t-1}$ & $\gamma_{2}$ & $4.01(1.00)$ & $* * *$ & & & \\
\hline$I N F L I_{i, t-1}$ & $\gamma_{3}$ & $6.93(2.26)$ & $* *$ & $9.5000(2.80)^{* * *}$ & & \\
\hline$G G D P_{i, t-1}$ & $\gamma_{4}$ & & & & & \\
\hline$D G F I_{i, t-1}$ & $\gamma_{5}$ & $0.05(0.03)$ & & $0.0700(0.03)^{*}$ & $0.05(0.03)$ & $0.09(0.03)^{* *}$ \\
\hline$X R F I_{i, t-1}$ & $\gamma_{6}$ & $1.99(0.67)$ & $* *$ & $1.6500(0.66)^{*}$ & & \\
\hline$\sigma_{i, t}$ & $\nu$ & $-1.40(0.30)$ & $* * *$ & $-0.9700(0.29)^{* * *}$ & $-0.69(0.17)^{* * *}$ & $-0.85(0.47) \cdot$ \\
\hline \multirow{2}{*}{\multicolumn{2}{|c|}{$\begin{array}{r}\text { Degrees of freedom } \\
\text { Log-likelihood }\end{array}$}} & 528 & & 534 & 549 & 566 \\
\hline & & 1531.0 & & 1501.3 & 1538.2 & 1514.5 .7 \\
\hline Country fixed effects & $\alpha_{i}$ & yes & & yes & yes & yes \\
\hline Time fixed effects & $\lambda_{t}$ & yes & & no & yes & no \\
\hline
\end{tabular}

Signif. codes: $0^{(* * *)} 0.001^{\text {(**) }} 0.01^{\text {(*) }} 0.05^{(\cdot)} 0.1$

Notes: This table reports the semi-elasticities of the joint estimation of (24) using maximum likelihood, explaining the conditional $s d$ of annual growth rates of real GDP per capita. Asymptotic standard errors are in parentheses.

variance equation (24b). Observe that compared to system (19), only the conditional variance now appears as an additional control in the growth equation.

The results are shown in Table 8. Our estimates suggest that not only do our measures remain significant, volatility also has a negative partial correlation with growth. We compare a specification similar to Ramey and Ramey using government-spending induced volatility as a control variable (iv) to specifications where we add tax rates (iii). Taxes are remarkably significant and the volatility-growth link becomes more precise. Further, we add shocks from forecasting equations for the inflation rate and the real effective exchange rate (ii), and use a specification which includes all variables that have been identified as potential control variables (i). Our results confirm a robust negative link between volatility and growth. Accounting for more heterogeneity indeed strengthens the negative link between volatility and growth among OECD countries. $^{21}$

\section{Conclusions}

The aim of this paper is to shed light on the link between taxes and output volatility. We start from a theoretical perspective demonstrating that distortional taxes affect the

\footnotetext{
${ }^{21}$ Note that the Levine-Renelt variables are fully captured by country-specific effects. Adding taxes or time fixed-effects in the growth equation (not shown) even increases the level of economic and statistical significance for tax rates in the conditional variance equation.
} 
variability of macro aggregates in the stochastic neoclassical model. Contrary to conventional perceptions, we show that the second moment rather than the first moment of output growth rates is affected by taxes. In any non-linear DSGE model, individual decisions have indirect influence on macro volatility because they affect the variability of capital rewards, which corresponds to the volatility of capital dynamics, through their consumption-savings decision. In addition, the model is calibrated to obtain tax semielasticities on output growth volatility.

Taking the model to the data, we make use of the heterogeneity of output volatility and tax rates to estimate tax effects on macro volatility using panel estimation techniques. Our study brings out some strong empirical regularities in output volatility among OECD countries. Using several measures of volatility and estimation techniques we find that taxes are economically important and robust determinants, explaining differences across countries and over time. Accounting for non-stationarity of taxes and output volatility, we find empirical evidence for a cointegrating relationship.

In particular, and in accordance with our theoretical results, we find that tax effects are not unidirectional: while the labor and the corporate income tax are negatively correlated, the capital tax is positively correlated with output volatility. Accounting for potential outliers even strengthens the case for taxes. Indeed taxes are among the robust determinants such as inflation and effective exchange rate variability. In contrast, financial development was not found to be robust. We also confirm a strong empirical link between volatility and growth (Ramey and Ramey 1995). Allowing for more heterogeneity in the conditional variance equation indeed strengthens the observed empirical link.

\section{References}

Acemoglu, D., S. Johnson, J. Robinson, and Y. Thaicharoen, "Institutional causes, macroeconomic symptoms: Volatility, crises and growth," J. Monet. Econ., 2003, $50,49-123$.

Ait-Sahalia, Yacine, "Closed-form likilihood expansions for multivariate diffusions," $A n$ nals of Statistics, 2008, 36 (2), 906-937.

Auerbach, Alan J. and Joel Slemrod, "The Economic Effects of the Tax Reform Act of 1986," J. Econ. Lit., 1997, 35, 589-632.

Ball, Laurence, "Why does high inflation raise inflation uncertainty," J. Monet. Econ., 1992, 29, 371-388. 
Banerjee, Anindya, "Panel data unit roots and cointegration: An overview," Oxford Bull. Econ. Statist., 1999, pp. 607-629.

Bental, B. and D. Peled, "The accumulation of wealth and the cyclical generation of new technologies: A search theoretic approach," Int. Econ. Rev., 1996, 37 (3), 687-718.

Bilbiie, F. O., A. Meier, and G. J. Müller, "What accounts for the changes in U.S. fiscal policy transmission?," J. Money, Credit, Banking, 2008, 40 (7), 1439-1470.

Blanchard, Olivier and John Simon, "The long and large decline in U.S. output volatility.," Brookings Pap. Econ. Act., 2001, pp. 135-164.

Bollerslev, Tim, "Generalized autoregressive conditional heteroscedasticity," J. Econometrics, 1986, 31, 307-327.

Boucekkine, Raouf and Ramon Ruiz Tamarit, "Imbalance effects in the Lucas model: an analytical exploration," Topics in Macroecon., 2004, 4 (1), 1-17.

Bun, Maurice J.G. and Martin A. Carree, "Bias-Corrected Estimation in Dynamic Panel Data Models," J. Bus. Econ. Statist., 2005, 23 (2), 200-210.

Canova, Fabio, "What explains the great moderation in the U.S.? A structural analysis," Journal of the European Economic Association, 2009, 7 (4), 697-721.

Carey, David and Josette Rabesona, Tax Ratios on Labor and Capital Income and on Consumption, Cambridge, MA: in Peter Birch Sørensen, Ed., Measuring the Tax Burden on Capital and Labor, CESifo seminar series, 2004.

Cecchetti, Stephen G., Alfonso Flores-Lagunes, and Stefan Krause, "Assessing the Sources of Changes in the Volatility of Real Growth," NBER, 2006, 11946.

Chang, Fwu-Ranq, "The Inverse Optimal Problem: A Dynamic Programming Approach," Econometrica, 1988, 56 (1), 147-172.

Chari, V. V., Patrick J. Kehoe, and Ellen R. McGrattan, "Business Cycle Accounting," Econometrica, 2007, 75 (3), 781-836.

Denizer, Cevdet, Murat Iyigun, and Ann L. Owen, "Finance and macroeconomic volatility," Contrib. to Macroecon., 2002, 2 (1).

Francois, Patrick and Huw Lloyd-Ellis, "Animal spirits trough creative destruction," Amer. Econ. Rev., 2003, 93 (3), 530-550. 
_ and _ _ "Implementation Cycles, Investment, and Growth," Int. Econ. Rev., 2008, 49 (3), 901-942.

Giles, Christopher and Paul Johnson, "Tax Reforms in the UK and Changes in the Progressivity of the Tax System, 1985-95," Fisc. Stud., 1995, 15 (3), 64-86.

Greenwood, Jeremy and Gregory W. Huffman, "Tax Analysis in a Real-Business-Cycle Model," J. Monet. Econ., 1991, 27, 167-190.

Jaimovich, Nir and Henry E. Siu, "The Young, the Old, and the Restless: Demographics and Business Cycle Volatility," Amer. Econ. Rev., 2009, 99 (3), 804-826.

Justiniano, Alejandro and Giorgio E. Primiceri, "The time-varying volatility of macroeconomic fluctuations," Amer. Econ. Rev., 2008, 98 (3), 604-641.

Kim, Chang-Jin and Charles R. Nelson, "Has the U.S. economy become more stable? A Bayesian approach based on a Markov-Switching model of the business cycle," Rev. Econ. Statist., 1999, 81 (4), 608-616.

Kydland, Finn E. and Edward C. Prescott, "Time to build and aggregate fluctuations," Econometrica, 1982, 50 (6), 1345-1370.

Lensink, Robert and Bert Scholtens, "Financial development and the transmission of monetary shocks," University of Groningen, Research Institute, 2004, (04E05).

Long, John B. Jr. and Charles I. Plosser, "Real Business Cycles," J. Polit. Economy, 1983, 91 (1), 39-69.

Matsuyama, Kiminori, "Growing through cycles," Econometrica, 1999, 67 (2), 335-347.

McConnel, Margaret and Gabriel Perez-Quiros, "Output fluctuations in the U.S.: What has changed since the early 1980's?," Amer. Econ. Rev., 2000, 90 (5), 1464-1476.

Mendoza, Enrique G., Assaf Razin, and Linda L. Tesar, "Effective tax rates in macroeconomics: Cross-country estimates of tax rates on factor incomes and consumption," J. Monet. Econ., 1994, 34, 297-323.

Merton, Robert C., "An asymptotic theory of growth under uncertainty," Rev. Econ. Stud., 1975, 42 (3), 375-393.

Nelson, Daniel B., "Conditional Heteroskedasticity in Asset Returns: A New Approach," Econometrica, 1991, 59 (2), 347-370. 
Nickell, Stephen, "Biases in Dynamic Models with Fixed Effects," Econometrica, 1981, 49 (6), 1417-1426.

Pedroni, Peter, "Panel cointegration: Asymptotic and finite sample properties of pooled time series tests with an application to the PPP hypothesis," Econometric Theory, 2004, 20, 597-625.

Posch, Olaf, "Structural estimation of jump-diffusion processes in macroeconomics," $J$. Econometrics, 2009, forthcoming.

_ _ and Klaus Wälde, "Natural volatility, welfare and taxation," CESifo, 2006, 1748.

Ramey, Gary and Valerie A. Ramey, "Cross-country evidence on the link between volatility and growth," Amer. Econ. Rev., 1995, 85 (5), 1138-1151.

Schmitt-Grohé, Stephanie and Martin Uribe, "Solving dynamic general equilibrium models using a second-order approximation to the policy function," J. Econ. Dynam. Control, 2004, 28, 755-775.

Smith, William T., "Inspecting the Mechanism Exactly: A Closed-form solution to a stochastic growth model," B.E. Journal of Macroeconomics, 2007, 7 (30), 1-31.

Sørensen, Michael, Likelihood Methods for Diffusions with Jumps, New York: in Prabhu and Basawa, Eds., Statistical Inference in Stochastic Processes, Dekker, Inc., 1991.

Stiroh, Kevin J., "Volatility accounting: a production perspective on increased economic stability," Journal of the European Economic Association, 2009, 7 (4), 671-696.

Stock, James H. and Mark W. Watson, "Forecasting inflation," J. Monet. Econ., 1999, 44, 293-335.

_

_ _ and _ _ "Understanding Changes in International Business Cycle Dynamics," Journal of the European Economic Association, 2005, 3 (5), 968-1006.

Turnovsky, S. J., Methods of Macroeconomic Dynamics, Cambridge, Massachusetts: MIT Press, Second Edition, 2000.

Wälde, Klaus, "Endogenous growth cycles," Int. Econ. Rev., 2005, 46 (3), 867-894.

Xie, Danyang, "Increasing returns and increasing rates of growth," J. Polit. Economy, 1991, 99 (2), 429-435. 
, "Divergence in Economic Performance: Transitional Dynamics with Multiple Equilibria," J. Econ. Theory, 1994, 63, 97-112.

\section{A Appendix}

\section{A.1 The model}

\section{A.1.1 The household's budget constraint (6)}

Nominal wealth is given by $\left(1+\tau_{c}\right) p_{t}^{C} a_{t}=k_{t} v_{t}$ where $k_{t}$ is the individual's capital, $v_{t}$ is the value of one unit of capital, and $p_{t}^{C}$ is the producer price of the consumption good. For investment being positive, the price of an installed good equals the price of a new investment good, $v_{t}=\left(1+\tau_{k}\right) p_{t}^{K}$, hence

$$
a_{t}=\frac{1+\tau_{k}}{1+\tau_{c}} k_{t}
$$

Households receive net capital income $\left(1-\tau_{i}\right) p_{t}^{Y} r_{t} k_{t}$ and net labor income $\left(1-\tau_{i}\right) p_{t}^{Y} w_{t}$ (after-tax value marginal products), which is used for saving and consumption. Define savings $p_{t}^{Y} s_{t} \equiv\left(1-\tau_{i}\right) p_{t}^{Y}\left(r_{t} k_{t}+w_{t}\right)-\left(1+\tau_{c}\right) p_{t}^{C} c_{t}$. A fraction $\frac{1-\tau_{i}}{1+\tau_{k}} \delta+\tau_{a}$ of the capital stock disappears as a result of depreciation and taxation,

$$
d k_{t}=\left\{\frac{p_{t}^{Y} s_{t}}{\left(1+\tau_{k}\right) p_{t}^{K}}-\frac{1-\tau_{i}}{1+\tau_{k}} \delta k_{t}-\tau_{a} k_{t}\right\} d t
$$

The relationship in (26) shows that a positive tax on wealth, $\tau_{a}$, simply increases the rate of effective depreciation. We show below $\tau_{a}$ also applies to real wealth, $a_{t}$, and not only to the number of machines, $k_{t}$. Using (25), the budget constraint reads

$$
d a_{t}=\frac{1+\tau_{c}}{1+\tau_{k}}\left\{\frac{s_{t}}{1+\tau_{k}}-\frac{1-\tau_{i}}{1+\tau_{k}} \delta k_{t}-\tau_{a} k_{t}\right\} d t .
$$

Inserting $s_{t}$, replacing $k_{t}$ with the definition in (25) and using (8) gives

$$
\begin{aligned}
d a_{t} & =\frac{1+\tau_{k}}{1+\tau_{c}}\left\{\frac{1-\tau_{i}}{1+\tau_{k}} r_{t} k_{t}+\frac{1-\tau_{i}}{1+\tau_{k}} w_{t}-\frac{1+\tau_{c}}{1+\tau_{k}} c_{t}-\frac{1-\tau_{i}}{1+\tau_{k}} \delta k_{t}-\tau_{a} k_{t}\right\} d t, \\
& \equiv\left\{\left(\frac{1-\tau_{i}}{1+\tau_{k}}\left(r_{t}-\delta\right)-\tau_{a}\right) a_{t}+\frac{1-\tau_{i}}{1+\tau_{c}} w_{t}-c_{t}\right\} d t
\end{aligned}
$$

where factor rewards are, $w_{t}=\frac{\partial Y_{t}}{\partial L} \equiv Y_{L}=(1-\alpha) Y_{t} / L$, and $r_{t}=\frac{\partial Y_{t}}{\partial K_{t}} \equiv Y_{K}=\alpha Y_{t} / K_{t}$.

\section{A.1.2 The budget constraint of the government (4)}

We start by summing up the budget constraint (6) using $\sum_{i=1}^{L} a_{t, i}=L a_{t}$ to obtain

$$
L d a_{t}=\left\{L\left(\frac{1-\tau_{i}}{1+\tau_{k}}\left(r_{t}-\delta\right)-\tau_{a}\right) a_{t}+L \frac{1-\tau_{i}}{1+\tau_{c}} w_{t}-C_{t}\right\} d t
$$


where $C_{t}$ denotes $C_{t}=L c_{t}$. Transforming $a_{t}$ into units of the capital stock from (25),

$$
a_{t}=\frac{1+\tau_{k}}{1+\tau_{c}} L k_{t} / L \equiv \frac{1+\tau_{k}}{1+\tau_{c}} K_{t} / L
$$

and insert it in the aggregated budget constraint yields

$$
\begin{aligned}
d\left(\frac{1+\tau_{k}}{1+\tau_{c}} K_{t}\right) & =\left\{\frac{1+\tau_{k}}{1+\tau_{c}} K_{t}\left(\frac{1-\tau_{i}}{1+\tau_{k}}\left(r_{t}-\delta\right)-\tau_{a}\right)+L \frac{1-\tau_{i}}{1+\tau_{c}} w_{t}-C_{t}\right\} d t \\
\Leftrightarrow d K_{t} & =\left\{\frac{1-\tau_{i}}{1+\tau_{k}}\left(Y_{K} K_{t}+Y_{L} L\right)-\left(\frac{1-\tau_{i}}{1+\tau_{k}} \delta+\tau_{a}\right) K_{t}-\frac{1+\tau_{c}}{1+\tau_{k}} C_{t}\right\} d t \\
& =\left\{\frac{1-\tau_{i}}{1+\tau_{k}} Y_{t}-\left(\frac{1-\tau_{i}}{1+\tau_{k}} \delta+\tau_{a}\right) K_{t}-\frac{1+\tau_{c}}{1+\tau_{k}} C_{t}\right\} d t
\end{aligned}
$$

where we used Euler's theorem, that is $Y_{t}=Y_{K} K_{t}+Y_{L} L$ in the last step. Finally, we rewrite $d K_{t} / d t=I_{t}-\delta K_{t}$, multiply by $\left(1+\tau_{k}\right)$ and insert $\left(1+\tau_{k}\right) I_{t}$ from $(7)$,

$$
\begin{aligned}
\left(1+\tau_{k}\right)\left(I_{t}-\delta K_{t}\right) & =\left(1-\tau_{i}\right)\left(Y_{t}-\delta K_{t}\right)-\tau_{a}\left(1+\tau_{k}\right) K_{t}-\left(1+\tau_{c}\right) C_{t} \\
\Leftrightarrow Y_{t}-C_{t}-I_{t} & =\tau_{k}\left(I_{t}-\delta K_{t}\right)+\tau_{i}\left(Y_{t}-\delta K_{t}\right)+\tau_{a}\left(1+\tau_{k}\right) K_{t}+\tau_{c} C_{t} \equiv G .
\end{aligned}
$$

\section{A.1.3 The maximized Bellman equation}

Define the value of an optimal program of (5) as

$$
V\left(a_{0}, A_{0}\right)=\max _{\left\{c_{t}\right\}_{t=0}^{\infty}}\left\{U_{0}\right\}
$$

which denotes the present discounted value of utility evaluated along the optimal program. Following the same steps as in Posch (2009), the Bellman equation reads

$$
\begin{gathered}
\rho V\left(a_{0}, A_{0}\right)=\max _{c_{0}}\left\{u\left(c_{0}\right)+V_{a}\left(a_{0}, A_{0}\right)\left(\left(\frac{1-\tau_{i}}{1+\tau_{k}}\left(r_{0}-\delta\right)-\tau_{a}\right) a_{0}+\frac{1-\tau_{i}}{1+\tau_{c}} w_{0}-c_{0}\right)\right. \\
\left.+V_{A} A_{t} \mu+\frac{1}{2} V_{A A} A_{t}^{2} \eta^{2}\right\}
\end{gathered}
$$

The first-order condition reads

$$
u^{\prime}\left(c_{0}\right)=V_{a}\left(a_{0}, A_{0}\right)
$$

making consumption a function of the state variables, $c=c\left(a_{0}, A_{0}\right)$, and

$$
\begin{aligned}
\rho V\left(a_{0}, A_{0}\right)= & u\left(c\left(a_{0}, A_{0}\right)\right)+\left(\frac{1-\tau_{i}}{1+\tau_{k}}\left(r_{0}-\delta\right) a_{0}-\tau_{a} a_{0}+\frac{1-\tau_{i}}{1+\tau_{c}} w_{0}-c\left(a_{0}, A_{0}\right)\right) V_{a} \\
& +V_{A} A_{0} \mu+\frac{1}{2} V_{A A} A_{0}^{2} \eta^{2} .
\end{aligned}
$$

is the the maximized Bellman equation. 


\section{A.2 Explicit solutions}

\section{A.2.1 Proof of Theorem 2.1}

The idea of this proof is to show that together with an educated guess of the value function, both the maximized Bellman equation (30) and first-order condition (29) are fulfilled. We may guess that the value function reads

$$
V\left(a_{t}, A_{t}\right)=\frac{\phi^{-\sigma} a_{t}^{1-\sigma}}{1-\sigma}+f\left(A_{t}\right)
$$

To start with we rewrite the policy function using the transformation in (28) as

$$
C_{t}=\frac{1+\tau_{k}}{1+\tau_{c}} \phi K_{t} \Leftrightarrow L c_{t}=\phi L a_{t} \Leftrightarrow c_{t}=\phi a_{t} .
$$

Using (29) together with (5), and (32), we obtain $V_{a}=\left(\phi a_{t}\right)^{-\sigma}$. Moreover, our guess in (31) implies $V_{A}=f_{A}, V_{A A}=f_{A A}$. Inserting everything into (30) gives

$$
\rho \frac{\phi^{-\sigma} a_{t}^{1-\sigma}}{1-\sigma}+g\left(A_{t}\right)=\frac{\left(\phi a_{t}\right)^{1-\sigma}}{1-\sigma}+\left(a_{t} \phi\right)^{-\sigma}\left(\frac{1-\tau_{i}}{1+\tau_{k}}\left(r_{t}-\delta\right) a_{t}-\tau_{a} a_{t}+\frac{1-\tau_{i}}{1+\tau_{c}} w_{t}-\phi a_{t}\right),
$$

where we defined $g\left(A_{t}\right) \equiv \rho f\left(A_{t}\right)-f_{A} A_{t} \mu-\frac{1}{2} f_{A A} A_{t}^{2} \eta^{2}$. Inserting factor rewards together with $K_{t} \equiv L k_{t}=\frac{1+\tau_{c}}{1+\tau_{k}} L a_{t}$ from (25), we obtain after some algebra,

$$
\begin{aligned}
\rho \frac{\phi^{-\sigma} a_{t}^{1-\sigma}}{1-\sigma}+g\left(A_{t}\right)= & \frac{\left(\phi a_{t}\right)^{1-\sigma}}{1-\sigma}+\frac{1-\tau_{i}}{1+\tau_{c}} A_{t}\left(\frac{1+\tau_{c}}{1+\tau_{k}}\right)^{\alpha} a_{t}^{\alpha}\left(a_{t} \phi\right)^{-\sigma} \\
& -\frac{1-\tau_{i}}{1+\tau_{k}} \delta a_{t}\left(a_{t} \phi\right)^{-\sigma}-\tau_{a} a_{t}\left(a_{t} \phi\right)^{-\sigma}-\phi a_{t}\left(a_{t} \phi\right)^{-\sigma} .
\end{aligned}
$$

Using $\alpha=\sigma$ and $g\left(A_{t}\right)=\frac{1-\tau_{i}}{1+\tau_{c}} A_{t}\left(\frac{1+\tau_{c}}{1+\tau_{k}}\right)^{\alpha} \phi^{-\sigma}$ which pins down $f(\cdot)$, it reads

$$
\begin{aligned}
\rho \frac{\phi^{-\sigma} a_{t}^{1-\sigma}}{1-\sigma} & =\frac{\left(\phi a_{t}\right)^{1-\sigma}}{1-\sigma}-\frac{1-\tau_{i}}{1+\tau_{k}} \delta a_{t}^{1-\sigma} \phi^{-\sigma}-\tau_{a} a_{t}^{1-\sigma} \phi^{-\sigma}-\left(\phi a_{t}\right)^{1-\sigma} \\
\Leftrightarrow \rho & =\phi-(1-\sigma)\left(\frac{1-\tau_{i}}{1+\tau_{k}} \delta+\tau_{a}\right)-(1-\sigma) \phi,
\end{aligned}
$$

which we finally can solve for $\phi$ in (10).

\section{A.2.2 The evolution of capital rewards}

Using Itô's formula (change of variables), capital rewards, $r_{t}=\alpha A_{t} K_{t}^{\alpha-1} L^{1-\alpha}$, follow

$$
d r_{t}=r_{A} d A_{t}+r_{K} d K_{t}=r_{t} \mu d t+r_{t} \eta d B_{t}+r_{K}\left(I_{t}-\delta K_{t}\right) d t,
$$

Now inserting $r_{K}=-(1-\alpha) r_{t} / K_{t}$, and replacing $Y_{t} / K_{t}=r_{t} / \alpha$, we obtain with (9)

$$
\begin{aligned}
d r_{t} & =r_{t} \mu d t+r_{t} \eta d B_{t}-(1-\alpha)\left(I_{t} / K_{t}-\delta\right) r_{t} d t \\
& =\left(\mu-(1-\alpha)\left(\frac{1-\tau_{i}}{1+\tau_{k}} r_{t} / \alpha-\frac{1-\tau_{i}}{1+\tau_{k}} \delta-\tau_{a}-\frac{1+\tau_{c}}{1+\tau_{k}} C_{t} / K_{t}\right)\right) r_{t} d t+r_{t} \eta d B_{t}
\end{aligned}
$$




\section{A.2.3 Proof of Corollary 2.2}

Inserting $C_{t}=\frac{1+\tau_{k}}{1+\tau_{c}} \phi K_{t}$ in the evolution of capital rewards (33), we obtain

$$
d r_{t}=\left(\mu-(1-\alpha)\left(\frac{1-\tau_{i}}{1+\tau_{k}} r_{t} / \alpha-\frac{1-\tau_{i}}{1+\tau_{k}} \delta-\tau_{a}-\phi\right)\right) r_{t} d t+r_{t} \eta d B_{t}
$$

We now rewrite the equation by using the condition $\alpha=\sigma$, and inserting $\phi$ from (10) to

$$
\begin{aligned}
d r_{t} & =\left(\mu-\frac{1-\alpha}{\alpha}\left(\frac{1-\tau_{i}}{1+\tau_{k}} r_{t}-\rho-\left(\frac{1-\tau_{i}}{1+\tau_{k}} \delta+\tau_{a}\right)\right)\right) r_{t} d t+r_{t} \eta d B_{t} \\
& =\frac{1-\alpha}{\alpha}\left(\frac{\alpha}{1-\alpha} \mu-\frac{1-\tau_{i}}{1+\tau_{k}} r_{t}+\frac{1-\tau_{i}}{1+\tau_{k}} \delta+\tau_{a}+\rho\right) r d t+r_{t} \eta d B_{t} \\
& =\frac{1-\alpha}{\alpha} \frac{1-\tau_{i}}{1+\tau_{k}} r_{t}\left(\frac{1+\tau_{k}}{1-\tau_{i}}\left(\frac{\alpha}{1-\alpha} \mu+\rho+\frac{1-\tau_{i}}{1+\tau_{k}} \delta+\tau_{a}\right)-r_{t}\right) d t+r_{t} \eta d B_{t}
\end{aligned}
$$

Using the definitions $c_{1}$ and $c_{2}$ we finally obtain (11).

\section{A.2.4 Proof of Corollary 2.3}

Recall that the differential for log output is

$$
d \ln Y_{t}=\left(\mu-\frac{1}{2} \eta^{2}+\frac{1-\tau_{i}}{1+\tau_{k}} r_{t}-\alpha \frac{1+\tau_{c}}{1+\tau_{k}} C_{t} / K_{t}-\alpha\left(\tau_{a}-\frac{1-\tau_{i}}{1+\tau_{k}} \delta\right)\right) d t+\eta d B_{t}
$$

Insert the policy function $C=\frac{1+\tau_{k}}{1+\tau_{c}} \phi K$ and use the condition $\alpha=\sigma$ gives for $y_{t} \equiv \ln Y_{t}$,

$$
d y_{t}=\left(\mu+\alpha\left(\frac{1-\tau_{i}}{1+\tau_{k}} r_{t} / \alpha-\frac{1-\tau_{i}}{1+\tau_{k}} \delta-\tau_{a}-\phi\right)-\frac{1}{2} \eta^{2}\right) d t+\eta d B_{t} .
$$

It denotes an affine SDE which solution is given by simple integration

$$
y_{t}=y_{t_{0}}+\left(t-t_{0}\right)\left(\mu-\rho-\tau_{a}-\frac{1-\tau_{i}}{1+\tau_{k}} \delta-\frac{1}{2} \eta^{2}\right)+\frac{1-\tau_{i}}{1+\tau_{k}} \int_{t_{0}}^{t} r_{s} d s+\eta\left(B_{t}-B_{0}\right),
$$

where $r_{t}$ is known explicitly (cf. Posch 2009). Moreover, using the production function (1), $\log$ output is $y_{t}=\ln A_{t}+\alpha \ln K_{t}+(1-\alpha) \ln L$. Now insert the solution $C_{t}=\frac{1+\tau_{k}}{1+\tau_{c}} \phi K_{t}$ from Theorem 2.1 and define $\Delta y_{t} \equiv y_{t}-y_{t-\Delta}$, to obtain

$$
\alpha\left(\ln C_{t}-\ln C_{t-\Delta}\right)=\Delta y_{t}-\left(\ln A_{t}-\ln A_{t-\Delta}\right)
$$

Inserting the solutions to the SDEs in (2), $\ln A_{t}-\ln A_{t-\Delta}=\left(\mu-\frac{1}{2} \eta^{2}\right) \Delta+\eta\left(B_{t}-B_{t-\Delta}\right)$, we obtain (12). Inserting the solution for $\log$ output (34) for $t_{0}=t-\Delta$ we obtain

$$
\begin{aligned}
\alpha\left(\ln C_{t}-\ln C_{t-\Delta}\right)= & \left(\mu-\rho-\tau_{a}-\frac{1-\tau_{i}}{1+\tau_{k}} \delta-\frac{1}{2} \eta^{2}\right) \Delta+\frac{1-\tau_{i}}{1+\tau_{k}} \int_{t-\Delta}^{t} r_{s} d s \\
& +\eta\left(B_{t}-B_{t-\Delta}\right)-\left(\left(\mu-\frac{1}{2} \eta^{2}\right) \Delta+\eta\left(B_{t}-B_{t-\Delta}\right)\right) \\
= & -\left(\rho+\tau_{a}+\frac{1-\tau_{i}}{1+\tau_{k}} \delta\right) \Delta+\frac{1-\tau_{i}}{1+\tau_{k}} \int_{t-\Delta}^{t} r_{s} d s .
\end{aligned}
$$

which for $\alpha=\sigma$ is (13). 


\section{A.2.5 An alternative solution}

The proofs for Theorem A.1, Corollaries A.2 and A.3 are analogous to Appendices A.2.1 to A.2.4 and available in a separate appendix on request from the author.

Theorem A.1 If $\sigma>1$ and the condition $\rho=(\alpha \sigma-1)\left(\frac{1-\tau_{i}}{1+\tau_{k}} \delta+\tau_{a}\right)-\sigma \mu+\frac{1}{2}(1+\sigma) \sigma \eta^{2}$ is fulfilled, consumption is a constant fraction of income, $C_{t}=\left(\frac{1+\tau_{k}}{1+\tau_{c}}\right)^{\alpha} \vartheta Y_{t}$, where

$$
\vartheta=\frac{\sigma-1}{\sigma} \frac{1-\tau_{i}}{1+\tau_{c}}\left(\frac{1+\tau_{c}}{1+\tau_{k}}\right)^{\alpha}
$$

Corollary A.2 The (before tax) rental rate of capital follows

$$
d r_{t}=c_{3} r\left(c_{4}-r_{t}\right) d t+\eta r_{t} d B_{t}
$$

where $c_{3} \equiv \frac{1-\alpha}{\alpha \sigma} \frac{1-\tau_{i}}{1+\tau_{k}}$, and $c_{4} \equiv \frac{\alpha \sigma}{1-\alpha} \frac{1+\tau_{k}}{1-\tau_{i}} \mu+\alpha \sigma \frac{1+\tau_{k}}{1-\tau_{i}}\left(\frac{1-\tau_{i}}{1+\tau_{k}} \delta+\tau_{a}\right)$.

Corollary A.3 The growth rate of output per unit of time, $\Delta y_{t} \equiv y_{t}-y_{t-\Delta}$, reads

$$
\Delta y_{t}=\left(\mu-\alpha\left(\frac{1-\tau_{i}}{1+\tau_{k}} \delta+\tau_{a}\right)-\frac{1}{2} \eta^{2}\right) \Delta+1 / \sigma \frac{1-\tau_{i}}{1+\tau_{k}} \int_{t-\Delta}^{t} r_{s} d s+\eta\left(B_{t}-B_{t-\Delta}\right)
$$

\section{A.2.6 Moments of capital rewards}

Consider the process in (11) or (37). Merton (1975) showed that $r_{t}$ has a limiting Gamma distribution. Thus all moments exist and are known. Alternatively, we may use the following approach which is based on SDEs. Because $\ln r_{t}$ is a smooth transformation of $r_{t}$, the sequence $\left\{\ln r_{t}\right\}_{t=t_{0}}^{\infty}$ converges in distribution to a random variable $\ln r$,

$$
\ln r_{t} \stackrel{\mathcal{D}}{\rightarrow} \ln r \quad \text { where } \quad-\infty<\ln r_{t}<\infty .
$$

Compute the stochastic differential $d \ln r_{t}=c_{1}\left(c_{2}-r_{t}\right) d t-\frac{1}{2} \eta^{2} d t+\eta d B_{t}$. Because it describes a smooth transformation of $r_{t}$, it has a unique limiting distribution. If we apply expectations to the integral version, letting $t \rightarrow \infty$ we obtain

$$
\begin{aligned}
\lim _{t \rightarrow \infty} E_{0}\left(\ln r_{t}\right)-\lim _{t \rightarrow \infty} E_{0}\left(\ln r_{t-\Delta}\right) & =\left(c_{1} c_{2}-\frac{1}{2} \eta^{2}\right) \Delta-\lim _{t \rightarrow \infty} \int_{t-\Delta}^{t} c_{1} E_{0}\left(r_{s}\right) d s \\
\Leftrightarrow 0 & =\left(c_{1} c_{2}-\frac{1}{2} \eta^{2}\right) \Delta-\lim _{t \rightarrow \infty} c_{1} E_{0}\left(r_{t}\right) \Delta \\
\Rightarrow E(r) & \equiv \lim _{t \rightarrow \infty} E_{0}\left(r_{t}\right)=\frac{c_{1} c_{2}-\frac{1}{2} \eta^{2}}{c_{1}}
\end{aligned}
$$

which is the asymptotic mean, i.e., the mean of the limiting distribution. 
Similarly, using the integral version of (11), asymptotically

$$
\begin{aligned}
\lim _{t \rightarrow \infty} E_{0}\left(r_{t}\right)-\lim _{t \rightarrow \infty} E_{0}\left(r_{t-\Delta}\right) & =\lim _{t \rightarrow \infty} \int_{t-\Delta}^{t}\left(c_{1} c_{2}\right) E_{0}\left(r_{s}\right) d s-\lim _{t \rightarrow \infty} \int_{t-\Delta}^{t} c_{1} E_{0}\left(r_{s}^{2}\right) d s \\
\Leftrightarrow 0 & =\lim _{t \rightarrow \infty}\left(c_{1} c_{2}\right) E_{0}\left(r_{t}\right) \Delta-\lim _{t \rightarrow \infty} c_{1} E_{0}\left(r_{t}^{2}\right) \Delta \\
\Rightarrow E\left(r^{2}\right) & \equiv \lim _{t \rightarrow \infty} E_{0}\left(r_{t}^{2}\right)=E(r) c_{2} .
\end{aligned}
$$

The variance of the limiting distribution is $\operatorname{Var}(r)=E\left(r^{2}\right)-E(r)^{2}=E(r) \frac{1}{2} \eta^{2} / c_{1}$.

\section{A.3 Volatility and taxation}

\section{A.3.1 A stochastic balanced growth property}

Lemma A.4 Given the restriction $\alpha=\sigma, \operatorname{Cov}\left(\ln C_{t}-\ln C_{t-\Delta}, B_{t}-B_{t-\Delta}\right)=0$.

Proof. Inserting $C_{t}=\frac{1+\tau_{k}}{1+\tau_{c}} \phi K_{t}$ from Theorem 2.1, we have to show that

$$
0=\operatorname{Cov}\left(\ln K_{t}-\ln K_{t-\Delta}, B_{t}-B_{t-\Delta}\right)=\operatorname{Cov}\left(\int_{t-\Delta}^{t} d\left(\ln K_{s}\right), \int_{t-\Delta}^{t} d B_{s}\right)
$$

which holds because from (3) $d \ln K_{t}=\left(I_{t} / K_{t}-\delta\right) d t$ is instantaneously deterministic.

We are prepared to compute moments of output growth rates. Using (12), we obtain

$$
E\left(\Delta y_{t}\right) \equiv \lim _{t \rightarrow \infty} E_{0}\left(\Delta y_{t}\right)=\left(\mu-\frac{1}{2} \eta^{2}\right) \Delta+\sigma \lim _{t \rightarrow \infty} E_{0}\left(\ln C_{t}-\ln C_{t-\Delta}\right)
$$

where from (13)

$$
\begin{aligned}
\sigma \lim _{t \rightarrow \infty} E_{0}\left(\ln C_{t}-\ln C_{t-\Delta}\right) & =\lim _{t \rightarrow \infty} \frac{1-\tau_{i}}{1+\tau_{k}} \int_{t-\Delta}^{t} E_{0}\left(r_{s}\right) d s-\left(\rho+\tau_{a}+\frac{1-\tau_{i}}{1+\tau_{k}} \delta\right) \Delta \\
& =\frac{1-\tau_{i}}{1+\tau_{k}} E(r) \Delta-\left(\rho+\tau_{a}+\frac{1-\tau_{i}}{1+\tau_{k}} \delta\right) \Delta=\frac{\alpha}{1-\alpha}\left(\mu \Delta-\frac{1}{2} \eta^{2} \Delta\right),
\end{aligned}
$$

using (40) in the last step. Plugging the result back into (41), we obtain the unconditional mean of output growth rates in (14). Observe that consumption and output asymptotically grow at the same exogenous rate, which is the stochastic equivalent to the balanced growth property in the standard neoclassical model.

\section{A.3.2 Moments of integrated capital rewards}

For the variance of output growth rates, we use (12) and Lemma A.4 to obtain (17), which shows it is given by the variance of consumption growth rates and the variance of the shocks. To compute the variance of consumption growth rates, we start from (13),

$$
\lim _{t \rightarrow \infty} \sigma^{2} \operatorname{Var}_{0}\left(\ln C_{t}-\ln C_{t-\Delta}\right)=\lim _{t \rightarrow \infty} \operatorname{Var}_{0}\left(\frac{1-\tau_{i}}{1+\tau_{k}} \int_{t-\Delta}^{t} r_{s} d s\right)
$$


where the asymptotic variance of the integrated process (11) can be written as

$$
\lim _{t \rightarrow \infty} \operatorname{Var}\left(\int_{t-\Delta}^{t} r_{s} d s\right)=\lim _{t \rightarrow \infty} E_{0}\left(\int_{t-\Delta}^{t} \int_{t-\Delta}^{t} r_{s} r_{u} d s d u\right)-\lim _{t \rightarrow \infty}\left(\int_{t-\Delta}^{t} E_{0}\left(r_{s}\right) d s\right)^{2}
$$

Therefore, to compute the variance of the integrated process, we need joint moments $E\left(r_{s} r_{u}\right)$. Consider $s>u$, then $E\left(r_{s} r_{u}\right)=E\left(r_{u} E\left(r_{s} \mid r_{u}\right)\right)$. We use the deterministic Taylor expansion to compute the conditional expectation (e.g. Aït-Sahalia 2008),

$$
E\left(g\left(r_{s}\right) \mid r_{u}\right)=\sum_{i=0}^{k} \frac{\Delta^{i}}{i !} A^{i} g\left(r_{u}\right)+O\left(\Delta^{k+1}\right)
$$

where $A$ is the infinitesimal generator of the process, $A g(x)=c_{1} x\left(c_{2}-x\right) g^{\prime}(x)+\frac{1}{2} c_{3}^{2} x^{2} g^{\prime \prime}(x)$. The function $g(\cdot)$ is sufficiently differentiable. As a result, we obtain a closed-form expansion of the conditional expectation around $r_{u}$. Using $g(x)=x$, we obtain

$$
A x=c_{1} x\left(c_{2}-x\right), \quad A^{2} x=c_{1}^{2} c_{2} x\left(c_{2}-x\right)-c_{1}\left(c_{1} x\left(c_{2}-x\right) 2 x+\frac{1}{2} c_{3}^{2} x^{2} 2\right) .
$$

Using a second-order Taylor expansion (44), the conditional expectation reads

$$
E\left(r_{s} \mid r_{u}\right)=r_{u}+\left(c_{1} c_{2} r_{u}-c_{1} r_{u}^{2}\right) \Delta+\left(\frac{1}{2} c_{1}^{2} c_{2}^{2} r_{u}-c_{1}\left(\frac{3}{2} c_{1} c_{2}+\frac{1}{2} c_{3}^{2}\right) r_{u}^{2}+c_{1}^{2} r_{u}^{3}\right) \Delta^{2}+O\left(\Delta^{3}\right)
$$

Hence, we obtain for the joint moments

$$
\begin{aligned}
E\left(r_{s} r_{u}\right)=E\left(r_{u} E\left(r_{s} \mid r_{u}\right)\right)= & E\left(r_{u}^{2}\right)+\left(c_{1} c_{2} E\left(r_{u}^{2}\right)-c_{1} E\left(r_{u}^{3}\right)\right) \Delta \\
& +\left(\frac{1}{2} c_{1}^{2} c_{2}^{2} E\left(r_{u}^{2}\right)-c_{1}\left(\frac{3}{2} c_{1} c_{2}+\frac{1}{2} c_{3}^{2}\right) E\left(r_{u}^{3}\right)+c_{1}^{2} E\left(r_{u}^{4}\right)\right) \Delta^{2}+O\left(\Delta^{3}\right)
\end{aligned}
$$

and the variance of the integrated process in (43) reads

$$
\begin{aligned}
\lim _{t \rightarrow \infty} \operatorname{Var}\left(\int_{t-\Delta}^{t} r_{s} d s\right)= & E\left(r_{s} r_{u}\right) \Delta^{2}-E(r)^{2} \Delta^{2} \\
= & \operatorname{Var}(r) \Delta^{2}+\left(c_{1} c_{2} E\left(r^{2}\right)-c_{1} E\left(r^{3}\right)\right) \Delta^{3} \\
& +\left(\frac{1}{2} c_{1}^{2} c_{2}^{2} E\left(r^{2}\right)-c_{1}\left(\frac{3}{2} c_{1} c_{2}+\frac{1}{2} c_{3}^{2}\right) E\left(r^{3}\right)+c_{1}^{2} E\left(r^{4}\right)\right) \Delta^{4}+O\left(\Delta^{5}\right)
\end{aligned}
$$

Plugging the result back into (42) gives the variance of consumption growth in (16). Finally, neglecting third-order terms, and inserting the asymptotic variance of capital rewards as from Appendix A.2.6, gives our measure in (17). ${ }^{22}$

\footnotetext{
${ }^{22}$ The author thanks to Michael Sørensen for helpful discussions on this issue.
} 


\section{A.4 Empirical results}

\section{A.4.1 Simple and partial correlation of taxes and output volatility}

Figure A.1: Simple correlation of taxes and observed volatility (five-year fixed-windows)
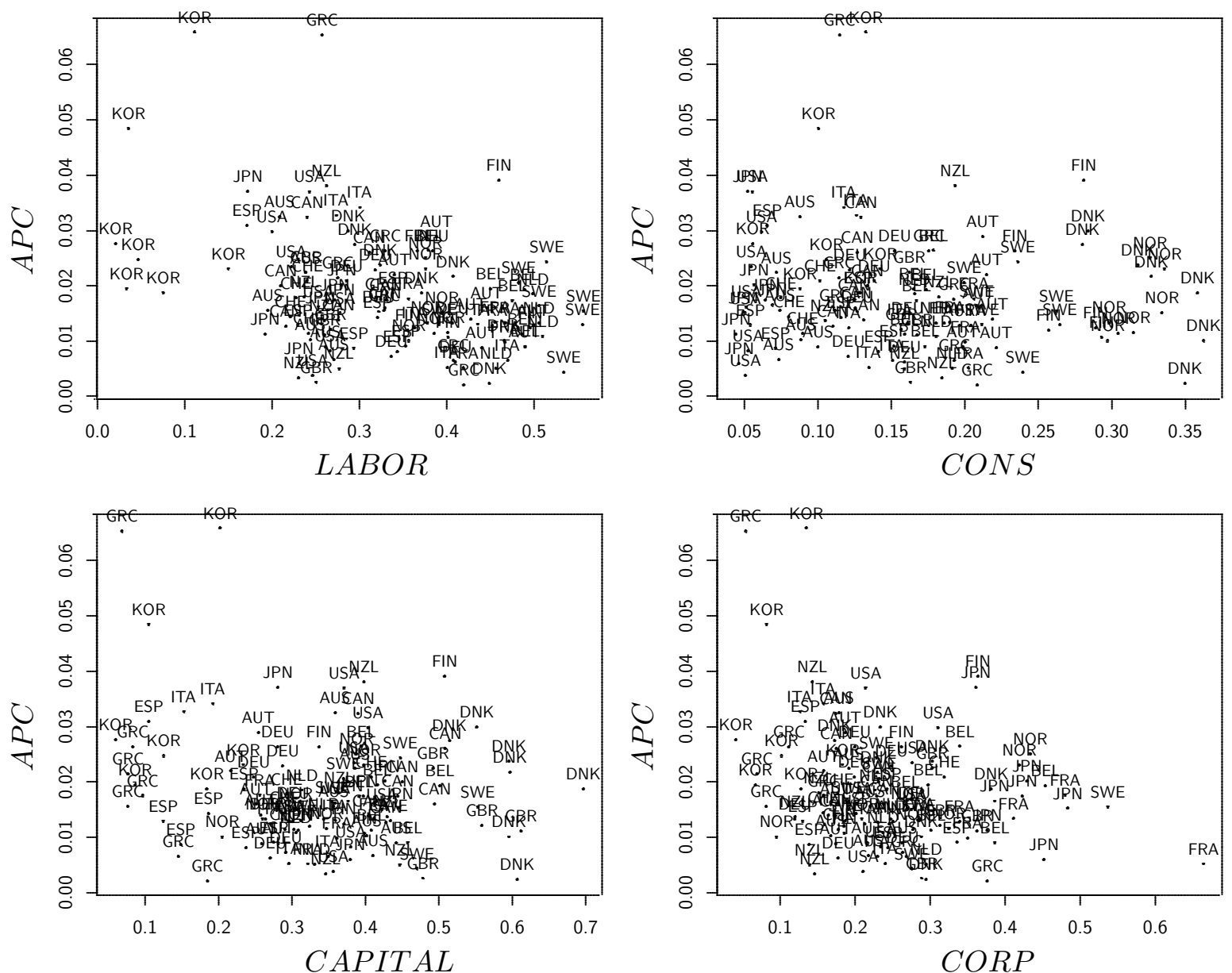

Notes: These figures give scatter plots of observed volatility measured as the $s d$ of annual growth rates of real GDP per capita against tax rates using the fixed-window (five-year) panel approach. 
Figure A.2: Partial correlation of taxes and observed volatility (five-year fixed-windows)
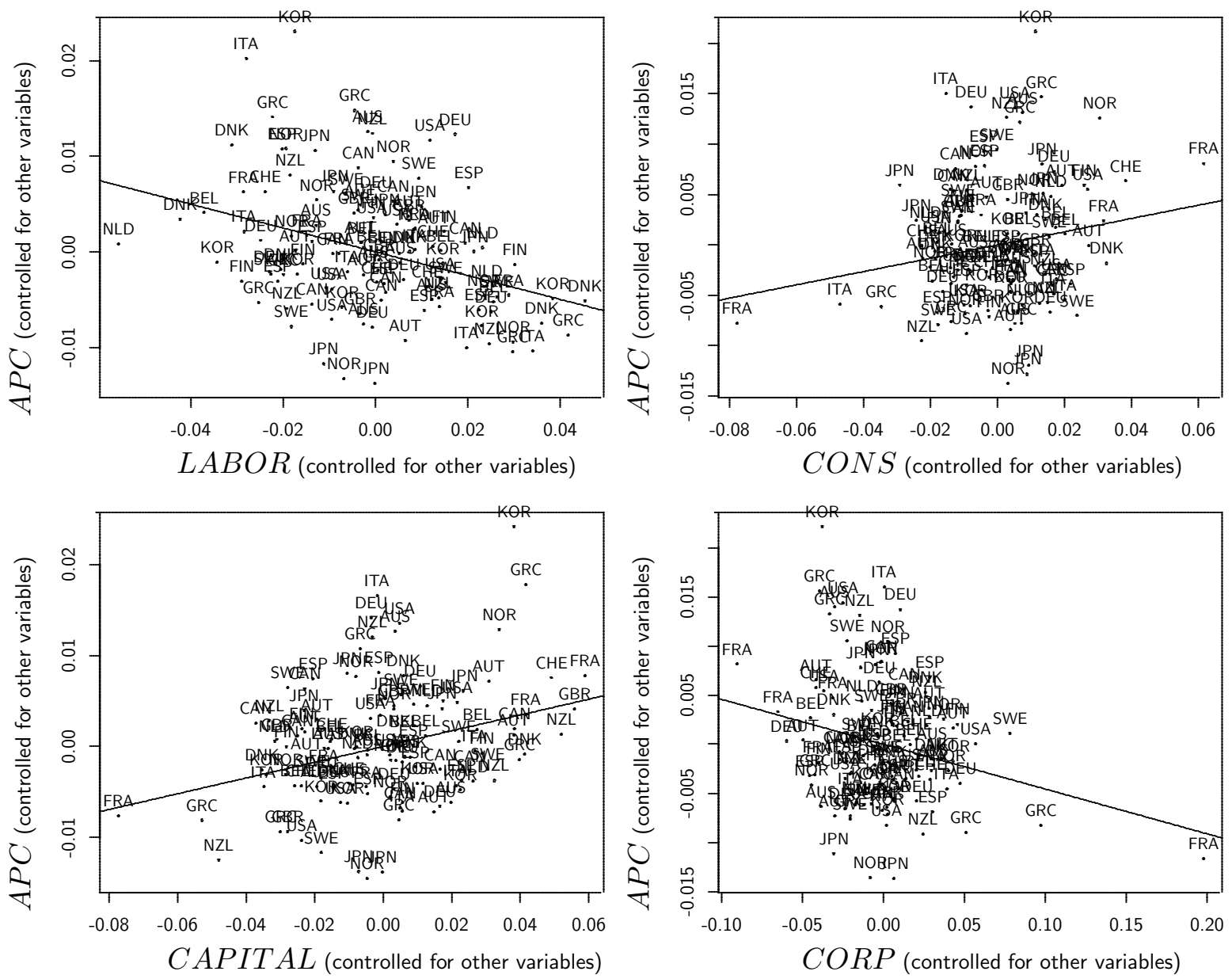

Notes: These figures give scatter plots of observed volatility measured as the $s d$ of annual growth rates of real GDP per capita against tax rates using the fixed-window (five-year) panel approach controlling for other effects (cf. Table 4, first column). 
Figure A.3: Simple correlation of taxes and observed volatility (ten-year fixed-windows)
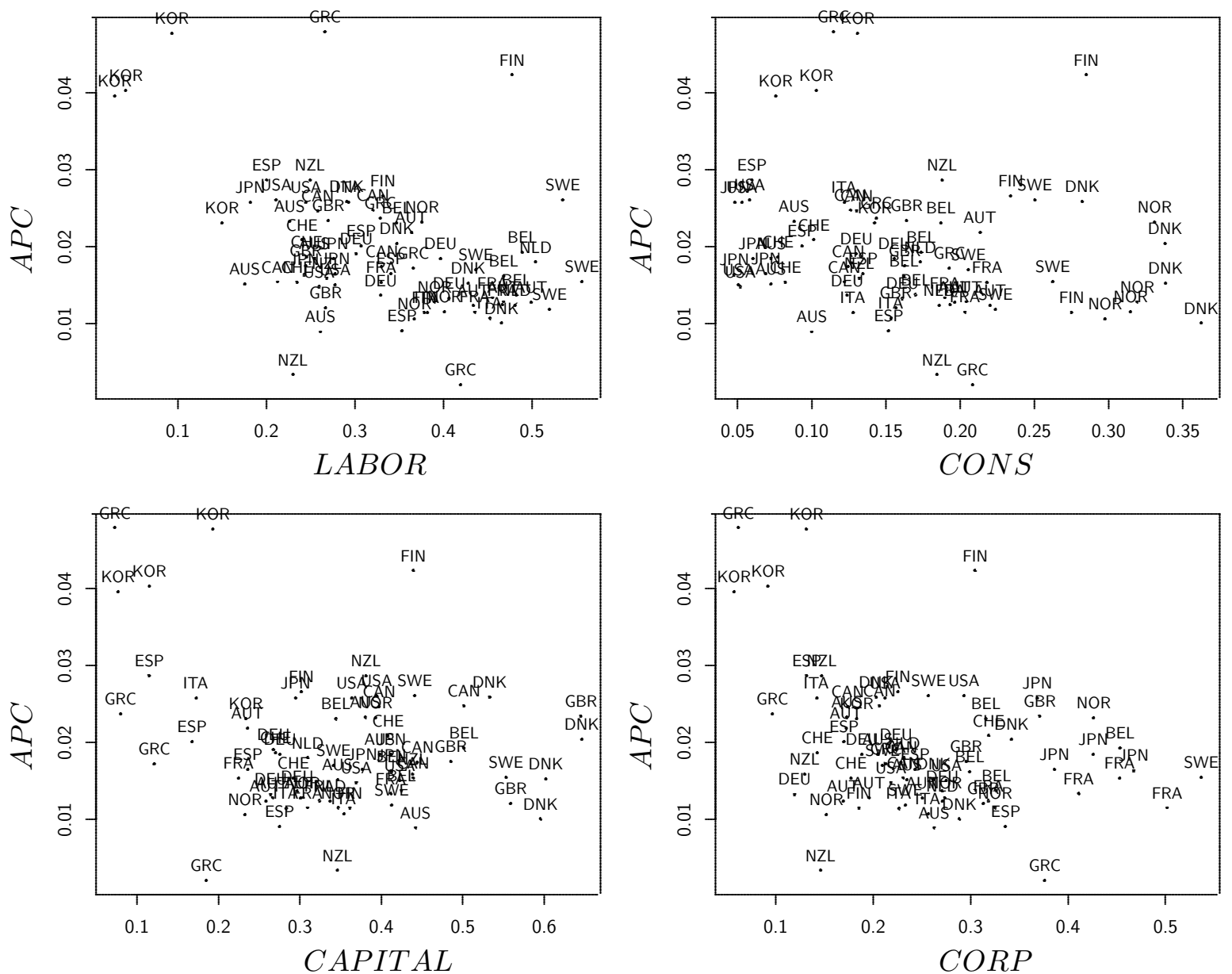

Notes: These figures give scatter plots of observed volatility measured as the sd of annual growth rates of real GDP per capita against tax rates using the fixed-window (ten-year) panel approach. 
Figure A.4: Partial correlation of taxes and observed volatility (ten-year fixed-windows)

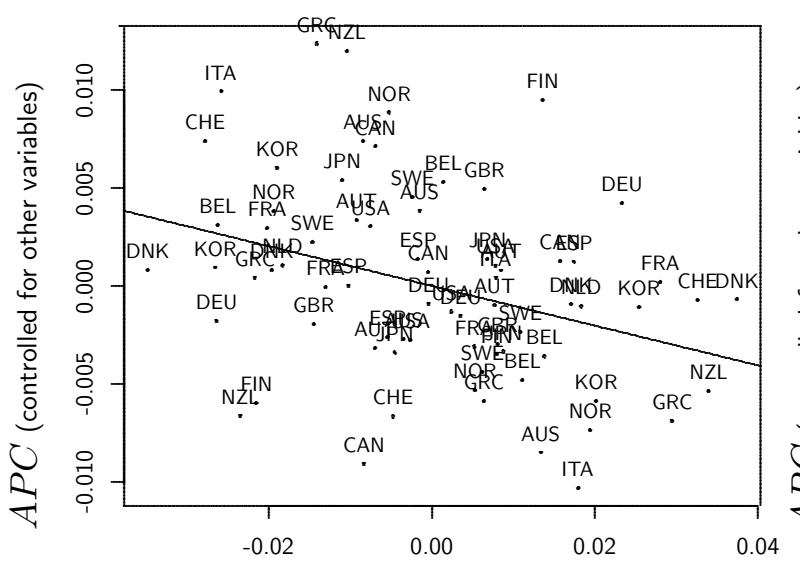

$L A B O R$ (controlled for other variables)

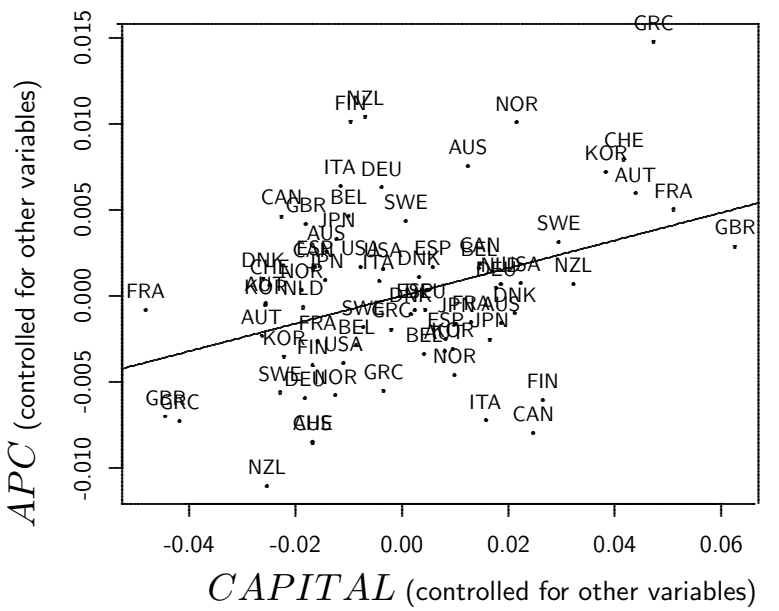

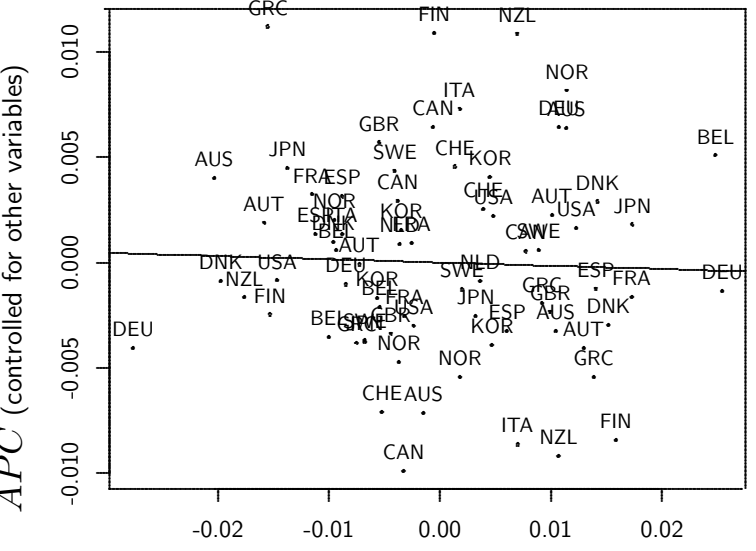

$C O N S$ (controlled for other variables)

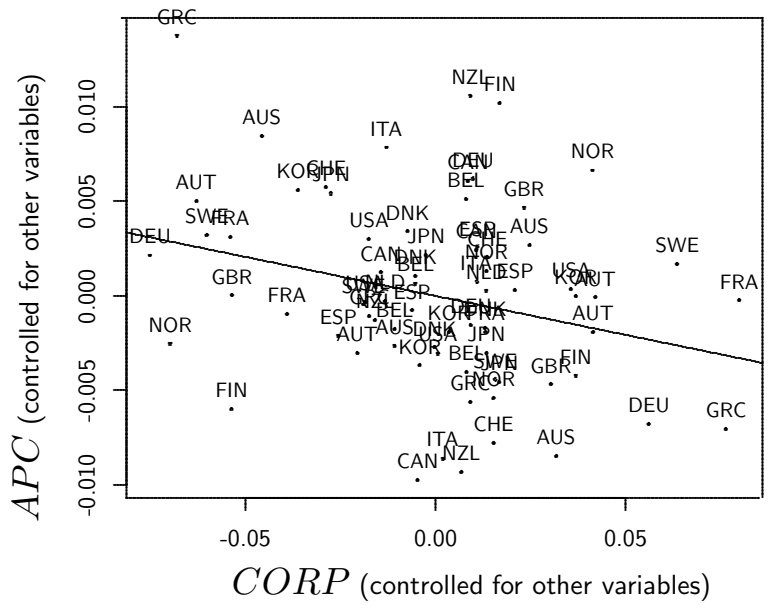

Notes: These figures give scatter plots of observed volatility measured as the $s d$ of annual growth rates of real GDP per capita against tax rates using the fixed-window (ten-year) panel approach controlling for other effects (cf. Table 4, third column). 


\section{CESifo Working Paper Series}

for full list see www.cesifo-group.org/wp

(address: Poschingerstr. 5, 81679 Munich, Germany, office@cesifo.de)

2689 Alexander Chudik, M. Hashem Pesaran and Elisa Tosetti, Weak and Strong Cross Section Dependence and Estimation of Large Panels, June 2009

2690 Mohamed El Hedi Arouri and Christophe Rault, On the Influence of Oil Prices on Stock Markets: Evidence from Panel Analysis in GCC Countries, June 2009

2691 Lars P. Feld and Christoph A. Schaltegger, Political Stability and Fiscal Policy - Time Series Evidence for the Swiss Federal Level since 1849, June 2009

2692 Michael Funke and Marc Gronwald, A Convex Hull Approach to Counterfactual Analysis of Trade Openness and Growth, June 2009

2693 Patricia Funk and Christina Gathmann, Does Direct Democracy Reduce the Size of Government? New Evidence from Historical Data, 1890-2000, June 2009

2694 Kirsten Wandschneider and Nikolaus Wolf, Shooting on a Moving Target: Explaining European Bank Rates during the Interwar Period, June 2009

2695 J. Atsu Amegashie, Third-Party Intervention in Conflicts and the Indirect Samaritan's Dilemma, June 2009

2696 Enrico Spolaore and Romain Wacziarg, War and Relatedness, June 2009

2697 Steven Brakman, Charles van Marrewijk and Arjen van Witteloostuijn, Market Liberalization in the European Natural Gas Market - the Importance of Capacity Constraints and Efficiency Differences, July 2009

2698 Huifang Tian, John Whalley and Yuezhou Cai, Trade Sanctions, Financial Transfers and BRIC's Participation in Global Climate Change Negotiations, July 2009

2699 Axel Dreher and Justina A. V. Fischer, Government Decentralization as a Disincentive for Transnational Terror? An Empirical Analysis, July 2009

2700 Balázs Égert, Tomasz Koźluk and Douglas Sutherland, Infrastructure and Growth: Empirical Evidence, July 2009

2701 Felix Bierbrauer, Optimal Income Taxation and Public Goods Provision in a Large Economy with Aggregate Uncertainty, July 2009

2702 Marc Gronwald, Investigating the U.S. Oil-Macroeconomy Nexus using Rolling Impulse Responses, July 2009

2703 Ali Bayar and Bram Smeets, Government Deficits in the European Union: An Analysis of Entry and Exit Dynamics, July 2009 
2704 Stergios Skaperdas, The Costs of Organized Violence: A Review of the Evidence, July 2009

2705 António Afonso and Christophe Rault, Spend-and-tax: A Panel Data Investigation for the EU, July 2009

2706 Bruno S. Frey, Punishment - and beyond, July 2009

2707 Michael Melvin and Mark P. Taylor, The Crisis in the Foreign Exchange Market, July 2009

2708 Firouz Gahvari, Friedman Rule in a Model with Endogenous Growth and Cash-inadvance Constraint, July 2009

2709 Jon H. Fiva and Gisle James Natvik, Do Re-election Probabilities Influence Public Investment?, July 2009

2710 Jarko Fidrmuc and Iikka Korhonen, The Impact of the Global Financial Crisis on Business Cycles in Asian Emerging Economies, July 2009

2711 J. Atsu Amegashie, Incomplete Property Rights and Overinvestment, July 2009

2712 Frank R. Lichtenberg, Response to Baker and Fugh-Berman's Critique of my Paper, "Why has Longevity Increased more in some States than in others?", July 2009

2713 Hans Jarle Kind, Tore Nilssen and Lars Sørgard, Business Models for Media Firms: Does Competition Matter for how they Raise Revenue?, July 2009

2714 Beatrix Brügger, Rafael Lalive and Josef Zweimüller, Does Culture Affect Unemployment? Evidence from the Röstigraben, July 2009

2715 Oliver Falck, Michael Fritsch and Stephan Heblich, Bohemians, Human Capital, and Regional Economic Growth, July 2009

2716 Wladimir Raymond, Pierre Mohnen, Franz Palm and Sybrand Schim van der Loeff, Innovative Sales, R\&D and Total Innovation Expenditures: Panel Evidence on their Dynamics, July 2009

2717 Ben J. Heijdra and Jochen O. Mierau, Annuity Market Imperfection, Retirement and Economic Growth, July 2009

2718 Kai Carstensen, Oliver Hülsewig and Timo Wollmershäuser, Price Dispersion in the Euro Area: The Case of a Symmetric Oil Price Shock, July 2009

2719 Katri Kosonen and Gaëtan Nicodème, The Role of Fiscal Instruments in Environmental Policy, July 2009

2720 Guglielmo Maria Caporale, Luca Onorante and Paolo Paesani, Inflation and Inflation Uncertainty in the Euro Area, July 2009 
2721 Thushyanthan Baskaran and Lars P. Feld, Fiscal Decentralization and Economic Growth in OECD Countries: Is there a Relationship?, July 2009

2722 Nadia Fiorino and Roberto Ricciuti, Interest Groups and Government Spending in Italy, 1876-1913, July 2009

2723 Andreas Wagener, Tax Competition, Relative Performance and Policy Imitation, July 2009

2724 Hans Fehr and Fabian Kindermann, Pension Funding and Individual Accounts in Economies with Life-cyclers and Myopes, July 2009

2725 Ernesto Reuben and Arno Riedl, Enforcement of Contribution Norms in Public Good Games with Heterogeneous Populations, July 2009

2726 Kurt Schmidheiny and Marius Brülhart, On the Equivalence of Location Choice Models: Conditional Logit, Nested Logit and Poisson, July 2009

2727 Bruno S. Frey, A Multiplicity of Approaches to Institutional Analysis. Applications to the Government and the Arts, July 2009

2728 Giovanni Villani, A Strategic R\&D Investment with Flexible Development Time in Real Option Game Analysis, July 2009

2729 Luca Di Corato and Michele Moretto, Investing in Biogas: Timing, Technological Choice and the Value of Flexibility from Inputs Mix, July 2009

2730 Gilad D. Aharonovitz, Nathan Skuza and Faysal Fahs, Can Integrity Replace Institutions? Theory and Evidence, July 2009

2731 Michele Moretto and Sergio Vergalli, Managing Migration through Conflicting Policies: an Option-theory Perspective, July 2009

2732 Volker Nitsch, Fly or Cry: Is Airport Noise Costly?, July 2009

2733 Francesco Cinnirella and Joachim Winter, Size Matters! Body Height and Labor Market Discrimination: A Cross-European Analysis, July 2009

2734 Samuel Bowles and Sandra Polanía Reyes, Economic Incentives and Social Preferences: A Preference-based Lucas Critique of Public Policy, July 2009

2735 Gary Burtless, Lessons of the Financial Crisis for the Design of National Pension Systems, July 2009

2736 Helmuth Cremer, Firouz Gahvari and Pierre Pestieau, Fertility, Human Capital Accumulation, and the Pension System, July 2009

2737 Hans Jarle Kind and Frank Stähler, Market Shares in Two-Sided Media Industries, July 2009 
2738 Pamela Campa, Alessandra Casarico and Paola Profeta, Gender Culture and Gender Gap in Employment, August 2009

2739 Sebastian Gechert, Supplementary Private Health Insurance in Selected Countries: Lessons for EU Governments?, August 2009

2740 Leif Danziger, Endogenous Monopsony and the Perverse Effect of the Minimum Wage in Small Firms, August 2009

2741 Yan Dong and John Whalley, A Third Benefit of Joint Non-OPEC Carbon Taxes: Transferring OPEC Monopoly Rent, August 2009

2742 Valentina Bosetti, Carlo Carraro and Massimo Tavoni, Climate Change Mitigation Strategies in Fast-Growing Countries: The Benefits of Early Action, August 2009

2743 Christina Felfe, The Willingness to Pay for Job Amenities: Evidence from Mothers' Return to Work, August 2009

2744 Jörg Franke, Christian Kanzow, Wolfgang Leininger and Alexandra Väth, Effort Maximization in Asymmetric N-Person Contest Games, August 2009

2745 Bruno S. Frey and Paolo Pamini, Making World Heritage Truly Global: The Culture Certificate Scheme, August 2009

2746 Frank N. Caliendo, Is Social Security behind the Collapse of Personal Saving?, August 2009

2747 Caterina Liesegang and Marco Runkel, Corporate Income Taxation of Multinationals and Fiscal Equalization, August 2009

2748 Chrysovalantou Milliou and Apostolis Pavlou, Upstream Horizontal Mergers and Efficiency Gains, August 2009

2749 Rüdiger Pethig and Christian Wittlich, Interaction of Carbon Reduction and Green Energy Promotion in a Small Fossil-Fuel Importing Economy, August 2009

2750 Kai Carstensen, Oliver Hülsewig and Timo Wollmershäuser, Monetary Policy Transmission and House Prices: European Cross-country Evidence, August 2009

2751 Olaf Posch, Explaining Output Volatility: The Case of Taxation, August 2009 